\title{
Hacia la elaboración de un Protocolo de Diseño Universal en la Universidad Nacional de Córdoba ${ }^{1}$
}

Toward the elaboration of a Universal Design Protocol in the National University of Córdoba

Mauricio Mareño, Cecilia Brissio, Flavia Ovejero

\section{Filiación}

Universidad Nacional de Córdoba, Argentina

E mail: mauriciomareno@gmail.com

Primera versión recibida en: 13 de abril de 2013

Última versión recibida en: 03 de junio de 2014

\section{Resumen}

El presente artículo intenta comunicar los elementos centrales del proceso de gestión de un Protocolo de Accesibilidad Urbana y Edilicia, fundado en los principios del Diseño Universal en la Universidad Nacional de Córdoba, Argentina.

Se exponen los conceptos principales que conforman la estructura teórica en la que se cimienta, planteándose la necesidad de superar concepciones tradicionales que aún prevalecen en las políticas de accesibilidad de las universidades de la región, y que resultan insuficientes para orientar el diseño de intervenciones respetuosas de derechos fundamentales. De esta manera, se propone resignificar los conceptos de discapacidad y accesibilidad desde un enfoque de derechos.

En tanto documento institucional, el Protocolo tiene por objetivo orientar el diseño y construcción del espacio urbano y edilicio de esta universidad, para que sea utilizable por todas las personas de manera autónoma, segura y sin restricciones. En ese sentido, se esbozan algunas condiciones institucionales indispensables para garantizar su efectiva implementación.

\section{Palabras claves}

Diseño Universal; accesibilidad; protocolo de Accesibilidad Urbana y Edilicia.

\begin{abstract}
This article is aimed at expressing the main aspects of the process of administration of an Urban and Building Protocol of Accessibility based on the principles of Universal Design in the National University of Cordoba in Argentina.

The main concepts that form the theoretical structure are outlined, posing the need to overcome traditional conceptions which still remain in the policies of accessibility in regional universities and which are insufficient to guide the design of a respectful intervention of fundamental rights. In this way, the concepts of disability and accessibility should be redefined from a perspective of rights.

This institutional protocol has as its main objective the guidance of the design and construction of an urban and building space for this university so it can be useful for all the people in a safe, self-sufficient-unexclusive way. Thus, some essential institutional conditions are outlined to guarantee its effective implementation.
\end{abstract}

\section{Key words \\ Universal Design; Accessibility; Urban and Building Protocol of Accessibility.}

1 Una versión preliminar de este trabajo se presentó como ponencia en el "Primer Encuentro Regional de Accesibilidad y Universidad de las Facultades la Asociación de Facultades y Escuelas de Arquitectura Públicas del Mercosur (ARQUISUR): Accesibilidad: Compromiso Social y Responsabilidad Profesional para un Diseño Inclusivo". Organizado por el Centro de Investigación de Barreras Arquitectónicas, Urbanísticas y en el Transporte (CIBAUT) y la Comisión Pro Medios Accesibles (COPROMA) de la Facultad de Arquitectura, Diseño y Urbanismo de la Universidad de Buenos Aires (UBA) y la Secretaría de Extensión de la Facultad de Arquitectura, Urbanismo y Diseño de la Universidad Nacional de Mar del Plata. Buenos Aires, 22 y 23 de octubre de 2012. 


\section{Sumario}

Introducción

1 Contexto de surgimiento del Protocolo

2 Redefiniendo la discapacidad y la accesibilidad desde un enfoque de derechos.

3 Características centrales del proceso de gestión del Protocolo: interdisciplinariedad y producción multiactoral.

4 El Protocolo. ¿Qué es? ¿Cómo se organiza y cuáles son sus componentes?

Algunas conclusiones

Bibliografía

\section{Introducción}

Este trabajo pretende exponer los elementos centrales del proceso de gestión interdisciplinaria y participativa de un Protocolo de Accesibilidad Urbana y Edilicia, en la Universidad Nacional de Córdoba (UNC), Argentina.

La UNC constituye la institución de educación superior universitaria más antigua de Argentina, y la cuarta que se fundó en América Latina. A lo largo de sus 400 años de historia pasó de ser un espacio de formación de elites a una universidad masiva, actualmente la segunda en envergadura a nivel nacional.

Desde el año 2006 la UNC inicia un proceso institucional de diseño e implementación de políticas de accesibilidad. Si bien el establecimiento del Protocolo de pautas de accesibilidad urbana y edilicia se inscribe en este proceso, su elaboración se origina en la necesidad de abordar algunos problemas referidos específicamente a la dimensión física de la accesibilidad, en una coyuntura de significativa expansión y crecimiento de la infraestructura edilicia². Entre los más importantes podemos citar: la ausencia de pautas y directrices que orienten la elaboración de estrategias y lineamientos de actuación en materia de accesibilidad urbana y edilicia, desde la perspectiva del Diseño Universal; la carencia de criterios unificados sobre accesibilidad, seguridad, comunicación y ordenamiento territorial en el diseño, construcción, ampliación o refacción del entorno urbano y los edificios; el desconocimiento respecto a la accesibilidad en los directivos y profesionales responsables de la gestión del espacio urbano y edilicio de la UNC.

Cabe subrayar que estos problemas tienen como escenario un contexto espacial altamente complejo, considerando sus dimensiones, su gran variedad edilicia y su distribución geográfica en la ciudad. La UNC posee una superficie total de $11.677 .835 \mathrm{~m}^{2}$ y una superficie edificada que alcanza los $369.985 \mathrm{~m}^{2}$. Cuenta actualmente con 242 edificios ${ }^{3}$ que albergan 13 Facultades, 103 Centros de Investigación y Servicios, 2 Colegios de Nivel Medio y Terciario, 25 Bibliotecas, 17 Museos, 2 Hospitales Universitarios y 2 Observatorios, entre otras dependencias académicas, culturales y administrativas ${ }^{4}$. Gran parte de ellas se ubican en Ciudad Universitaria, campus de la universidad que abarca $1.239 .426 \mathrm{~m}^{2}$ y que constituye el ámbito principal de la vida académica, cultural, social y política de la UNC. El resto se asientan en

2 Según datos oficiales, desde el año 2007 hasta el año 2012 la UNC incrementó la superficie edificada en 38.251 m2 (UNC, 2012).

3 Datos actualizados a febrero del 2014, obtenidos por el Sistema SIU-Querandíes de la Secretaría de Políticas Universitarias, a través de la Dirección de Catastro de la Subsecretaría de Planeamiento Físico de la UNC.

4 Programa de Estadísticas Universitarias, 2013. 
diferentes sectores de la ciudad de Córdoba 5 . En el año 2013, 131.911 personas transitaron y usaron cotidianamente sus espacios e instalaciones urbanas y edilicias, de las cuales 120.055 son estudiantes, 8.191 docentes y 3.665 no docentes ${ }^{6}$. Universo de personas que equivale al $10 \%$ de la población de la ciudad de Córdoba7. Este número representaría la cantidad de usuarios "directos" de las intervenciones y cambios que propone el Protocolo, sin reparar en aquellos usuarios "indirectos" considerando que la UNC se inserta en la trama y la dinámica urbana de la ciudad.

En este contexto, el Protocolo, en tanto documento institucional, tiene por objetivo orientar el diseño y construcción del espacio urbano y edilicio de la UNC, para que sea utilizable por todas las personas de manera autónoma, segura y sin restricciones.

El artículo se organiza en cinco apartados. En primer lugar, se describe el contexto de surgimiento del Protocolo, el cual se inscribe en un proceso institucional de gestión de políticas de accesibilidad e inclusión educativa en la UNC. En segundo término, se exponen las principales categorías teóricas que lo fundamentan, a saber, discapacidad y accesibilidad. Se señala la necesidad de reconceptualizarlas superando esquemas de interpretación tradicionales que resultan insuficientes para comprender su complejidad, y por ende, para orientar el diseño de intervenciones respetuosas de derechos fundamentales. Posteriormente se precisan las características centrales de su proceso de gestión: la interdisciplinariedad y la producción multiactoral. En cuarto lugar, se comunican los ejes y dimensiones que conforman el Protocolo, y finalmente se reflexiona sobre su impacto potencial, y sobre las condiciones institucionales necesarias que garanticen su efectiva implementación.

\section{Contexto de surgimiento del Protocolo}

Sin intención de realizar una exhaustiva historización, podemos plantear que en la UNC el proceso institucional de diseño e implementación de políticas de accesibilidad e inclusión educativa se inicia en el año 2006, a partir del diseño del Plan de Supresión de Barreras Arquitectónicas en Ámbitos Universitarios, por la Subsecretaría de Planeamiento Físico dependiente de la Secretaría de Planificación y Gestión Institucional. Su primera etapa, denominada de "Accesibilidad Primaria", supuso la realización de intervenciones puntuales en los edificios de las unidades académicas, destinadas fundamentalmente a favorecer y garantizar el acceso a través de la ejecución de rampas de ingreso. También se ejecutaron vados en las esquinas de los cruces de calles del predio de Ciudad Universitaria y veredas peatonales donde se incorporaron bandas táctiles para personas ciegas o con disminución visual. A su vez se comenzaron a generar baños accesibles. En el año 2007 se implementaron cruces peatonales a nivel de vereda diseñados para que por ellos transiten peatones en general, priorizando a aquellos usuarios de sillas de ruedas. El objetivo de su instalación en la Ciudad Universitaria fue que los automotores reduzcan su velocidad para cruzarlos, teniendo en cuenta que es un sector de la ciudad con altísimo flujo de peatones. Por otro lado, se comenzaron a ejecutar módulos de estacionamiento exclusivo en las playas de estacionamiento existentes y en las proximidades de los accesos principales de los edificios de las unidades académicas y dependencias de la UNC.

A pesar de su importancia, estas obras, no dejaban de ser intervenciones que abordaban sólo una parte del problema de la inaccesibilidad en la UNC. No obstante, se transformaron en el punto de partida de un largo y complejo camino a la accesibilización del espacio público de esta universidad.

5 La Ciudad Universitaria concentra el 55\% del total de las construcciones (133 edificios), el $45 \%$ restante (109) se distribuye por la ciudad de Córdoba.

6 Programa de Estadísticas Universitarias, 2013.

7 Instituto Nacional de Estadística y Censos (INDEC). Censo Nacional de Población, Hogares y Viviendas, 2010. 
Posteriormente, con la intención de consolidar este Plan y de ampliar el abordaje de la inaccesibilidad en la UNC, incorporando otras dimensiones además de la urbana-edilicia, en el 2008 se inicia un proceso de Diagnóstico Participativo que presentó como hito central la realización de las "Primeras Jornadas de Inclusión Educativa: Universidad y Discapacidad", en agosto de ese año. En estas Jornadas, la comunidad universitaria, priorizando la participación de aquellas personas catalogadas como discapacitadas, identificaron y analizaron las barreras institucionales al acceso, permanencia, avance y egreso de las carreras de la UNC. Además, se debatió colectivamente junto con actores institucionales responsables, las posibles soluciones a aquellos problemas reconocidos como prioritarios.

Como corolario de lo antes señalado, en el mes de noviembre se crea la Oficina de Inclusión Educativa de Personas en Situación de Discapacidad (OIE), espacio institucional dependiente de la Dirección de Inclusión Social de la Secretaría de Asuntos Estudiantiles de Rectorado, abocado a la coordinación, diseño y ejecución de programas de inclusión educativa y accesibilidad, en articulación con el resto de las dependencias y áreas institucionales de la UNC. Con su creación la UNC adopta institucionalmente la temática como objeto de política universitaria e ingresa a un debate ineludible en el campo de la educación superior.

Durante el período 2009, se articuló la propuesta de Diagnóstico Participativo iniciada en el año 2008 con la Fase I de Diagnóstico Situacional del "Programa de Accesibilidad en Universidades Nacionales" de la Secretaría de Políticas Universitarias del Ministerio de Educación de la Nación, implementado en todas las Universidades Nacionales del país. La Secretaría de Asuntos Estudiantiles a través de la OIE coordinó este Diagnóstico Situacional sobre las condiciones de accesibilidad de la UNC en articulación con la Subsecretaría de Planeamiento Físico.

En el marco del "Programa de Accesibilidad en Universidades Nacionales", en el año 2010 la UNC firma el Convenio-Programa con la Secretaría de Políticas Universitarias, obteniendo financiamiento para tres proyectos arquitectónicos que implican el desarrollo de circuitos mínimos accesibles (CiMA) en tres edificios de Ciudad Universitaria. Además de formalizar la obtención de financiamiento para obras de accesibilidad edilicia, la firma del citado ConvenioPrograma supuso el compromiso de la UNC a "garantizar el cumplimiento normativo en obras nuevas, remodelaciones y ampliaciones" (Res. SPU No 770/10). Posteriormente en el 2013 se aprobó el financiamiento para otros dos módulos (CiMA), a ejecutarse en el 2014. Estos nuevos módulos de accesibilidad comprenden un edificio y un importante sector del predio de Ciudad Universitaria. La financiación provista por este Programa, fortaleció y fortalece las obras de accesibilidad iniciadas por la Subsecretaría de Planeamiento Físico en el año 2006.

En el marco de este proceso, en el que se promovió el establecimiento de la accesibilidad como uno de los ejes de las políticas institucionales de la UNC, en el año 2011 el Honorable Consejo Superior encomienda la elaboración de pautas de accesibilidad que incorporen la perspectiva del diseño universal en toda la obra pública de la UNC, tanto en las refacciones como en los nuevos proyectos. Para ello se propone el trabajo articulado entre la Subsecretaría de Planeamiento Físico y la Dirección de Inclusión Social, dependencia a la pertenece la OIE. La gestión del Protocolo de Accesibilidad Urbana y Edilicia pretende constituir una primera respuesta institucional a esta solicitud.

\section{Redefiniendo la discapacidad y la accesibilidad desde un enfoque de derechos.}

Como se planteó anteriormente, el Protocolo se asienta en una estructura teórica que pretende superar las concepciones tradicionales sobre la discapacidad y la accesibilidad. Concepciones que aún predominan en nuestro medio y que orientan gran parte de las políticas de accesibilidad en las Universidades y en el sistema educativo en general. Revisaremos brevemente estos dos conceptos.

Se puede argumentar que el Protocolo se basa en una concepción de la discapacidad influenciada por el denominando "modelo social", específicamente por la corriente de los 
Disabilty Studies ${ }^{8}$. El modelo social supone una reacción a las perspectivas medicalizadas a partir de las cuales se interpreta, define y aborda la discapacidad de manera tradicional. Esta visión ortodoxa de la discapacidad", denominada "modelo médico" ${ }_{-}{ }^{9}$ o "modelo individual"11 la define como condición y atributo personal, confiriéndole un origen exclusivamente biológico. Analiza la discapacidad en términos de consecuencias a largo plazo de las enfermedades, los traumatismos y otros trastornos, y de sus repercusiones en la vida del individuo ${ }^{12}$. Se considera que la Organización Mundial de la Salud (OMS) a través de su Clasificación Internacional de las Deficiencias, Discapacidades y Minusvalías (CIDDM) de 1980, constituye la síntesis de los enfoques individuales de la discapacidad del siglo XX.

Para la CIDDM-OMS las consecuencias y repercusiones de las enfermedades se expresan en tres niveles: orgánico, personal y social, en ese sentido su estructura conceptual se basa en las siguientes definiciones:

- Deficiencia es toda pérdida o anormalidad de una estructura o función psicológica, fisiológica o anatómica.

- Discapacidad es toda restricción o ausencia -debida a una deficiencia- de la capacidad de realizar una actividad en la forma o dentro del margen que se considera normal para un ser humano.

- Minusvalía es una situación desventajosa para un individuo determinado, consecuencia de una deficiencia o una discapacidad, que limita o impide el desempeño de un rol que es normal en su caso (en función de su edad, sexo o factores sociales y culturales) ${ }^{13}$.

En síntesis, el modelo individual representado en la CIDDM alude a la discapacidad en términos de consecuencias de enfermedad, situando su causa en lo que el saber médico denomina anomalía o deficiencia, ya sea física, psíquica o sensorial. Es decir, la construye como consecuencia de un déficit a ser erradicado -en la medida de lo posible- a partir de la rehabilitación médica. De esta manera, instala "la dificultad" en el individuo que no puede adaptarse a las necesidades y exigencias del sistema social en el cual está inserto.

En los años '60 y '70 del siglo XX varios activistas y organizaciones de personas nominadas como discapacitadas de Europa y EEUU, comenzaron a reflexionar críticamente sobre el fenómeno desde su experiencia personal, cuestionando y rechazando los postulados del modelo médico de la OMS. En ese marco, la Unión de Personas con Deficiencias Físicas contra la Segregación (UPIAS) -según las siglas en inglés de Union of Physically Impaired Against Segregation-, considerada la primera organización en el Reino Unido compuesta y presidida exclusivamente por personas con deficiencias físicas (tal como ellos se auto-referenciaban) ${ }^{14}$, propone una reconceptualización de la discapacidad que posteriormente sería adoptada por

8 Los Disability Studies surgen en algunas universidades del Reino Unido a mediados de los años '70 del siglo XX, como un cuestionamiento al abordaje exclusivo de la temática de la discapacidad detentado por las ciencias médicas. Esta corriente académica propone una investigación emancipatoria e interdisciplinaria, a través de la articulación de la sociología, la economía, la antropología, la educación, la filosofía, la geografía, la ciencia política, entre otras disciplinas. Aborda cuestiones como la desigualdad, la exclusión y la discriminación a la que son sometidas las personas catalogadas como discapacitadas en las sociedades democráticas contemporáneas. Actualmente varias universidades de países europeos y del mundo anglosajón poseen centros o equipos de Disability Studies, que si bien presentan diferencias, comparten un núcleo común (Barton, 2009).

9 Barnes, 1998.

10 De Jong, 1979; Hahn, 1985; Abberley, 1998; Barton, 1998; OMS, 2001; Egea García y Sarabia Sánchez, 2001, 2004; Romañach y Lobato, 2005.

11 Oliver, 1990 a, 1990 b.

12 OMS, 1994.

13 Ibíd.

14 Hunt, 2001 
otras confederaciones, organizaciones y activistas del resto de occidente ${ }^{15}$. Así UPIAS redefine la discapacidad a partir de su diferenciación de la concepción de deficiencia: la deficiencia es definida como la carencia parcial o total de uno o todos los miembros, o la posesión de un miembro, órgano o mecanismo del cuerpo defectuoso y la discapacidad como la desventaja o la limitación en la actividad causada por una organización social contemporánea, que tiene escasa o ninguna consideración por las personas con deficiencias físicas, y que por lo tanto, las excluye de la corriente principal de las actividades sociales ${ }^{16}$.

La discapacidad es resignificada como una realidad producida a partir de las estructuras sociales, económicas y políticas vigentes en las sociedades occidentales. Representa una forma específica de opresión social, una situación impuesta a las personas con deficiencias físicas por la forma en que se las aísla y excluye innecesariamente de la plena participación en la sociedad. En esta lógica, es la sociedad quien discapacita a las personas con deficiencias físicas, quienes configuran, por lo tanto, un grupo social oprimido ${ }^{17}$. De esta manera uno de los pilares de la reivindicación política que propone UPIAS es la lucha por cambiar la organización de la sociedad, es decir, transformar las maneras en que se organiza la educación, la salud, la recreación, el transporte, el hábitat para que se tornen accesibles a las personas con deficiencias físicas.

Posteriormente a inicios de los años '80, el sociólogo inglés Michael Oliver denominaría a este enfoque "modelo social de la discapacidad". Según este autor, el modelo social se convirtió en un "concepto básico sobre el que los discapacitados empezaron a interpretar sus propias experiencias y a organizar su propio movimiento político"18. En esa línea, Barnes sostiene que el modelo:

... es un intento coordinado de politizar la discapacidad con el fin de mostrar un foco claro e inequívoco sobre las verdaderas y múltiples privaciones impuestas a aquellas personas cuyas condiciones biológicas son consideradas socialmente inaceptables, para producir un cambio estructural y cultural radical19.

Esta perspectiva significó una ruptura con las maneras tradicionales de entender el fenómeno, principalmente porque su manera de concebirlo no atribuye la culpa de la discapacidad a las propias personas nombradas como discapacitadas, sino a las modalidades dominantes de organización social. En ese sentido, su presupuesto fundamental alega que las causas que originan la discapacidad no son biológicas, sino sociales ${ }^{20}$.

El modelo social, al igual que el individual, ha sido centro de múltiples críticas. Algunos autores plantean que es un enfoque reduccionista, excesivamente radical y que debe complementarse con argumentos más racionales, pues actualmente son demasiado apasionados ${ }^{21}$, que presenta un análisis paradojal ya que pretende hacer caso omiso de todo acceso al problema desde el aspecto de la deficiencia, pero proclama que las barreras sociales levantadas contra ella demandan un análisis específico ${ }^{22}$, que la población definida como discapacitada no debería ser considerada una minoría oprimida en este momento de la historia ${ }^{23}$, que su aplicabilidad en la práctica desencadena consecuencias problemáticas ${ }^{24}$.

15 Oliver, 1986, 1990a, 1998.

16 UPIAS, 1975, 1976.

17 UPIAS, 1975; Oliver, 1990c.

18 Oliver, 1998.

19 Barnes, 2003.

20 UPIAS, 1975, 1976; Oliver, 1986, 1990a, 1990b, 1998; Finkelstein, 1980; Hahn, 1985.

21 Verdugo Alonso, 2003.

22 Stiker, 1999.

23 Batavia, 2001; Gallagher, 2003.

24 Humphrey, 2000. 
Sin intención de ingresar en estos debates, se considera que esta perspectiva presenta al menos cinco aportes respecto al modelo individual, que constituyen una contribución fundamental para redefinir el fenómeno y, por ende, orientar la investigación y la intervención en este campo desde una perspectiva crítica: a) Incorpora la experiencia personal de las personas definidas como discapacitadas al análisis y construcción del fenómeno, como de sus necesidades, demandas y de las eventuales modalidades de resolución; b) Trasciende la medicalización del fenómeno a partir de la incorporación de las estructuras económicas, culturales y políticas de la sociedad como condiciones objetivas determinantes. El contexto ya no es concebido como mero escenario, como en el modelo individual, ahora se constituye en un actor categórico; c) Reconoce a las personas con deficiencias físicas como personas con derechos civiles, políticos, económicos, sociales y culturales, a diferencia del modelo medicalizado donde se los concibe como sujetos enfermos a rehabilitar, como sujetos pasivos merecedores de caridad estatal. En ese sentido, supone un giro conceptual hacia un enfoque de derechos humanos; d) Construye la discapacidad como una situación social creada por los hombres, diferenciándola del concepto de deficiencia, que alude a una condición biológica. En ese sentido, la discapacidad es descripta por primera vez en términos de restricciones impuestas socialmente a las personas con deficiencias físicas; e) Visibiliza un aspecto que el modelo individual no puede develar, a saber, las situaciones de opresión impuestas a las personas con deficiencias debido a las formas de organización de las sociedades democráticas: segregación, aislamiento, carencia de control sobre sus propias vidas. De esta forma, incorpora la dimensión política al análisis del fenómeno ya que sus planteos permiten reflexionar sobre las posibilidades de inclusión de estas personas en el marco de las modalidades de organización social vigentes ${ }^{25}$.

Sin embargo, pese a estos aportes presenta tres importantes limitaciones: a) Su estructura conceptual no incorpora a las deficiencias en el análisis del fenómeno, subestimando su incidencia en las vidas de las personas definidas como discapacitadas; b) Supone que esta población conforma un todo homogéneo, desconociendo las heterogeneidades existentes al interior de este grupo poblacional; c) No logra desligarse de la supuesta normalidad biomédica característica del modelo individual. Es decir, al referirse a deficiencias, insuficiencias, limitaciones, alteraciones, miembros defectuosos, etc., se basa en el mismo patrón biológicomédico que estructura el modelo individual. En este sentido, pese a la crítica y objeción a este modelo, paradójicamente, comparte con él lo que Oliver ${ }^{26}$ denomina "la ideología de la normalidad". Dicho de otro modo, el enfoque social distingue acertadamente discapacidad de deficiencia, sin embargo, esta última mantiene aún su carácter de anormalidad. No plantea normalizar los cuerpos, como en el modelo individual, pero éstos continúan siendo percibidos y aceptados como cuerpos anormales ${ }^{27}$.

A inicios del siglo XXI, los postulados del modelo social inspiraron el desarrollo del denominado "modelo de la diversidad", cuyos principales referentes definen como una derivación y superación del modelo social ${ }^{28}$. Este modelo supone un sustancial cambio terminológico y conceptual ya que propone un nuevo concepto expresado en el término diversidad funcional para sustituir a otros de semántica peyorativa como discapacidad, minusvalía, invalidez, etc. ${ }^{29}$. Este nuevo concepto pretende eliminar la negatividad en la definición de estas personas y reforzar su esencia de diversidad. Partiendo del reconocimiento de que la diversidad es un atributo inherente a la propia existencia del ser humano, el modelo se refiere a personas con cuerpos u órganos que funcionan de manera diferente a la mayoría estadística de la sociedad, y

25 Mareño Sempertegui, 2010, 2011.

26 Oliver, 1990 a.

27 Ibíd.

28 Palacios y Romañach, 2006.

29 Romañach y Lobato, 2005; Palacios y Romañach, 2006. 
que por motivo de esa diferencia, realizan las tareas habituales de todo humano de maneras diferentes a las convencionales, es decir, a las consideradas normales ${ }^{30}$.

En coherencia con sus planteos relacionados a la diversidad humana, este enfoque cuestiona de manera consistente la noción de normalidad. Se expone que las maneras en que se construye el entorno dependen de lo que se ha enseñado que es normal en sentido estadístico. Así, se alude que lo normal es solo una ficción estadística de carácter meramente instrumental que se refiere a lo corriente, a lo más frecuente. Bajo esa lógica, se ha creado una sociedad en la que no se ha considerado la posibilidad de contemplar plenamente la diversidad en todos sus ámbitos. Por el contrario en la construcción del entorno social, físico y mental, ha primado la discriminación de todo aquel que es diferente ${ }^{31}$.

Según esta perspectiva, pese a su imperfección intrínseca, las sociedades occidentales han establecido un modelo de perfección que ninguno de sus miembros puede alcanzar, y que define la manera de ser física, sensorial o psicológica, como así también las reglas de funcionamiento social. Este modelo estaría relacionado con las ideas de perfección y normalidad establecidas por un amplio sector que detenta el poder y por el concepto de mayorías meramente cuantitativas. En ese sentido, afirman que las personas con diversidad funcional son discriminadas por su condición biológica, por su corporeidad diferente a la de la mayor parte de la población, que no les permite realizar las mismas funciones de igual manera que esa mayoría32.

El modelo de la diversidad, discutible en varios aspectos debido a su incipiente desarrollo conceptual ${ }^{33}$, quizás presente como mayor aporte el derribar "el mito del cuerpo perfecto" 34 , el mito del cuerpo completo proclamado por el saber médico occidental. Es decir, supera el principio subyacente a partir del cual se construyen los modelos de la OMS ${ }^{35}$ y el modelo social, que parece ser asumido como natural. Se hace alusión al supuesto de la normalidad biomédica. Por el contrario esta perspectiva se fundamenta en el principio de la diversidad humana concebida como una característica inherente y constitutiva del hombre y la sociedad ${ }^{36}$.

Tomando algunos aportes del modelo social y del modelo de la diversidad y desde una perspectiva de derechos humanos, el Protocolo define a la discapacidad como las limitaciones en la actividad y las restricciones en la participación generadas por contextos, entornos, bienes y servicios pensados, diseñados y construidos según parámetros convencionales y estereotipos de normalidad, que no contemplan la heterogeneidad inherente a la condición humana. Concebir la discapacidad desde esta perspectiva significa entenderla no como una condición o un atributo personal, sino como una situación construida social y culturalmente, una creación humana que todos los actores sociales producimos día a día a partir de actitudes, decisiones, acciones y omisiones fundadas en la naturalización de patrones de normalidad. De este modo, se trasciende la medicalización y la individualización del fenómeno a través de la incorporación del entorno físico, social y actitudinal como factores determinantes, que se constituirán en barreras o facilitadores, según limiten y/o dificulten la actividad y participación de una persona, o la faciliten y/o mejoren. Desde esta perspectiva, entonces, la discapacidad se revela como una cuestión situacional y relativa al contexto, no como un atributo que porta y predetermina a una persona. Somos personas situadas, sujetos situados, estamos permanentemente en

30 Ibíd.

31 Romañach y Lobato, 2005.

32 Palacios y Romañach, 2006.

33 Cuestión que por razones de espacio no desarrollaremos aquí.

34 Barnes, 1998.

35 Cabe señalar que en el 2001 la OMS publica una nueva clasificación con el nombre de "Clasificación Internacional del Funcionamiento, de la Discapacidad y de la Salud" (CIF). Producto de la revisión de la CIDDM de 1980, la CIF se autoproclama como un intento de integración de los modelos médico y social.

36 Mareño Sempertegui, 2010. 
situación, en diversas situaciones. Estamos situados en contextos que pueden ser accesibles o inaccesibles, amigables o poco amigables, respetuosos o irrespetuosos, favorecedores 0 limitantes, emancipadores o restrictivos. Es la situación construida, que involucra aspectos físicos, sociales, culturales, políticos, económicos y actitudinales la que limita o no limita, la que permite 0 no permite, la que posibilita 0 no posibilita; independientemente de las características personales o corporales de las personas que participen de ella. En ese sentido, el Protocolo hace referencia a "personas en situación de discapacidad" para aludir a aquellos sectores poblacionales tradicionalmente nominados como lisiados, impedidos, minusválidos, deficientes, discapacitados o personas con discapacidad, según diversos momentos históricos y perspectivas teóricas medicalizadas.

Ahora bien, evidentemente existen algunas limitaciones en las actividades o en las funciones corporales (definidas socialmente como discapacidades) derivadas de enfermedades como el reumatismo, la esclerosis múltiple, la atrofia muscular espinal, la distrofia muscular, la osteoporosis, entre otras. Algunas de las personas que presentan estas enfermedades exhiben dificultades en la realización de ciertas actividades cotidianas y por ende requieren apoyo para asearse, vestirse, trasladarse, alimentarse, etc. Sin embargo, incluso en estos casos, se considera que sus posibilidades de participación plena y efectiva en las esferas de la sociedad, en condiciones de equidad, se encuentran condicionadas por factores contextuales, tanto físicos, sociales como actitudinales. Es decir, se pone el acento en un contexto normalizador que genera limitaciones en la actividad y restricciones en la participación en personas cuyos cuerpos divergen de los patrones dominantes de plenitud corporal. Reconociendo que algunas de estas personas pueden presentar limitaciones en la actividad derivadas de enfermedades, es decir, ligadas a la posesión de un cuerpo enfermo.

Como se observa, este planteo no supone la omisión o la negación ingenua de la dimensión corporal de la discapacidad, la cual implica la existencia real de condiciones bio-físicas y/o sensorio-motoras en las personas. Condiciones que son concebidas como atributos que pueden derivarse de configuraciones genéticas, enfermedades, cambios corporales propios de la vejez, accidentes, etc. Estos atributos son reconocidos, pero no como expresión de "lo anormal", sino como una manifestación más de la heterogeneidad humana. Sin embargo, en contextos estandarizados e inequitativos como los predominantes en las sociedades occidentales, esos atributos se constituyen en situaciones de desventaja y de desigualdad. Es decir, a pesar de que la heterogeneidad constituye un atributo inmanente a la propia existencia del ser humano, ser diferente a la generalidad estadística de la población implica convivir en desventaja en un contexto normalizante y normalizador ${ }^{37}$.

Por otro lado, la accesibilidad también es una noción a la que se le han asignado diversas interpretaciones y que ha sido abordada desde diferentes enfoques, posiblemente por su carácter multidimensional. De esta manera, algunas de sus acepciones son parciales y otras incluso ambiguas. Aún en la actualidad "no existe una definición generalizada o comúnmente aceptada de accesibilidad"38.

Ahora bien, no obstante su carácter multívoco, la accesibilidad ha tenido un escaso desarrollo y profundización desde el punto de vista teórico y conceptual ${ }^{39}$. Algunas disciplinas como la arquitectura y la ergonomía, inicialmente, y más tarde el diseño, la comunicación, la informática y la ingeniería biomédica, entre otras, han abordado solo algunas aristas de este fenómeno complejo. En este marco, podemos afirmar que constituye una de esas nociones con

37 Mareño Sempertegui, 2011.

38 Alonzo López, 2002, 2007 b.

39 Ibíd. 
las cuales se argumenta pero sobre las cuales no se argumenta, ${ }^{40}$ en los espacios académicos, jurídicos y de gestión de políticas públicas.

En tanto fenómeno complejo, la accesibilidad se inscribe en la necesaria interacción entre el ser humano y el entorno construido, entendido este último no como un mero escenario o fuente de estímulos, sino como un complejo producido por el hombre que puede ofrecer oportunidades para la acción humana pero también obstáculos. Como señala Imrie ${ }^{41}$ "el carácter del funcionamiento cotidiano de las personas se entrelaza con la calidad del entorno diseñado". En ese sentido, se destaca que

Toda actividad ya sea individual o colectiva se realiza dentro de un entorno (entorno construido social y culturalmente) y, por tanto, las características de éste repercuten directamente sobre dicha actividad ${ }^{42}$, favoreciendo o limitando.

No obstante la amplitud que la accesibilidad presenta, habitualmente se ha tendido a identificarla de manera exclusiva con "aquellas prestaciones específicas que se han de proveer en las edificaciones y entornos públicos para algunas personas, especialmente para las que circulan en silla de ruedas" 43 . Concepción tradicional de la accesibilidad que se inscribe en la perspectiva del Diseño Libre de Barreras.

El Diseño Libre de Barreras o Diseño sin Barreras es concebido como un movimiento político y social que surgió en EEUU y Europa en la década del '50 del siglo XX, en el marco de las luchas por el reconocimiento de derechos civiles, impulsadas inicialmente por movimientos afroamericanos y de mujeres, y posteriormente, por personas definidas como discapacitadas. Se creó en respuesta a las demandas de generación de oportunidades educativas y en el empleo de veteranos de guerra y sus organizaciones, en un contexto en el que las barreras físicas del medio ambiente comienzan a ser reconocidas como un obstáculo significativo para las personas catalogadas como discapacitadas. Este movimiento inició un proceso de cambio en las políticas públicas y en la práctica del diseño y tuvo una influencia significativa en la legislación anglosajona sobre accesibilidad en las décadas del '70, ' 80 y '90 del siglo pasado44.

Inicialmente orientado al reconocimiento de los derechos de libre tránsito y acceso de usuarios de silla de ruedas, luego amplia el rango de destinatarios de la accesibilidad a todas las personas "con deficiencias de diferentes tipos". La Americans with Disabilities Act (ADA) de EEUU del año 1990, es considerada como la primera normativa de occidente que promovió esa amplitud de destinatarios ${ }^{45}$.

En esta perspectiva la accesibilidad es entendida como sinónimo de supresión de barreras arquitectónicas y en el transporte. Es decir, se fundamenta en la eliminación de obstáculos físicos a partir de la lógica de la adecuación y adaptación de los espacios e instalaciones existentes para el uso exclusivo de personas catalogadas como discapacitadas. Por ello, Mace ${ }^{46}$ plantea que el Diseño Libre de Barreras "es ante todo un movimiento centrado en la discapacidad".

Esta concepción de la accesibilidad presenta al menos tres características, estrechamente vinculadas entre sí:

40 Bourdieu y Wacquant, 2001. La cursiva pertenece a los autores.

41 Imrie, 2013.

42 Fundación ONCE, 2006.

43 Alonzo López, 2003.

44 Mace, Mueller y Story, 1998; Imrie y Gaete Reyes, 2009.

45 Ibíd.

46 Mace, 1998. 
a. Unidimensionalidad: Se refiere de manera exclusiva a la dimensión física del acceso, es decir, al desplazamiento, la circulación y la movilidad de las personas definidas como discapacitadas, en los entornos urbanos y en las edificaciones. Lo cual supone abordajes monodisciplinares. Esta concepción unidimensional de la accesibilidad entendida únicamente como accesibilidad física, se expresa en la definición propuesta en el "Concepto Europeo de Accesibilidad", documento de referencia en la temática promovido por la Comisión Europea a mediados de la década del '90 del siglo pasado: "La accesibilidad es la condición que posibilita el llegar, entrar, salir y utilizar las casas, las tiendas, los teatros, los parques y los lugares de trabajo"47.

b. Exclusividad de destinatarios: Se concibe como un beneficio exclusivo para aquellas personas nominadas como discapacitadas, ya que la supresión de barreras desde la lógica de la adaptación, permitiría que este sector poblacional pueda transitar y utilizar los espacios, ámbitos e instalaciones. Supone, por ende, la necesidad de un diseño especializado que contemple las características o "capacidades funcionales" de esta población. La actual Ley argentina sobre accesibilidad No 24.314/94: "Accesibilidad de personas con movilidad reducida", constituye un ejemplo significativo que grafica esta interpretación.

c. Segregación socio-espacial: Se trata de una accesibilidad no solo exclusiva, sino también excluyente ya que se basa en la generación de accesos, espacios e instalaciones específicas separadas de las de uso común. Esta "accesibilidad segregada"48 favorecería la segregación espacial e institucional de este sector poblacional en los ámbitos y espacios de uso. Por otro lado, algunos autores plantean que la utilización de un diseño especializado y de adaptaciones enfatiza la atención y la mirada sobre el estado corporal de sus usuarios, y por lo tanto puede ser un factor potencial de estigmatización49. En ese sentido, se formula que el Diseño Libre de Barreras en tanto diseño diferenciado, constituye un diseño discriminatorio ${ }^{50}$.

Esta concepción de accesibilidad comenzó a cuestionarse en las décadas del '70 y del '80 del siglo XX, proponiéndose como necesario un cambio de paradigma que supere el planteamiento unidimensional, reduccionista y mono-disciplinar de la accesibilidad.

Se hizo evidente que las características de accesibilidad segregada eran "especiales", más caras, y por lo general desagradables. También se puso de manifiesto que muchos de los cambios ambientales necesarios para albergar a las personas definidas como discapacitadas en realidad benefician a todos. A su vez, se reconoció que muchas prestaciones podían ser comúnmente provistas, menos costosas, sin etiquetas, e incluso, atractivas y comercializables. Estas observaciones fueron parte de un impulso político más amplio en el mundo anglosajón, que interpeló críticamente la normativa sobre accesibilidad basada en el Diseño Libre de Barreras sancionada en los albores de la segunda mitad del siglo XX. Se planteó que esas leyes proponían una serie de soluciones que eran problemáticas en tres aspectos: en primer lugar, reforzaron la provisión de vías de acceso separadas o segregadas para las personas catalogadas como discapacitadas, y confiaron demasiado en el equipamiento especializado o en las adaptaciones que hacen hincapié en la corporalidad de una persona. En segundo lugar, las adaptaciones en la construcción con demasiada frecuencia fueron mal hechas, lo que llevó a algunos observadores a sugerir que el diseño para este sector de la población comprometía las cualidades estéticas de los edificios. En tercer lugar, las soluciones de diseño giraron en torno a la provisión de acceso para usuarios de silla de ruedas y no atendieron a una gama más amplia de personas. Estos planteos fueron la base de una crítica de los enfoques tradicionales de

47 CEAPAT, 1996.

48 Mace, Mueller y Story, 1998.

49 Steinfeld, 2006 a, 2010; Imrie y Gaete Reyes, 2009; Imrie, 2012, 2013.

50 Rodríguez-Porrero, 2002; CEAPAT, 2008. 
diseño sin barreras, y sentaron las bases para el movimiento del Diseño Universal que propuso un nuevo enfoque para el acceso ${ }^{51}$.

Inicialmente formado por un grupo de arquitectos, diseñadores e investigadores en la década de 1980, este movimiento estableció unos principios fundamentales que rechazaban las soluciones de diseño segregadas o cualquier enfoque del acceso que no pueda incorporar y responder a la más amplia gama de características corporales. Uno de sus principales referentes es Ronald Mace (1941-1998) quien en 1985 utilizó por primera vez el término y fundó el Centro de Diseño Universal de la Universidad de Carolina del Norte (EEUU) en 1989. Mace es considerado el precursor de la arquitectura accesible contemporánea, ya que creó lo que habría de convertirse en un estándar de usabilidad que abarca a todas las personas.

El Diseño Universal constituye un paradigma del diseño y una concepción filosófica orientada a alcanzar la accesibilidad en los entornos, espacios, edificaciones, servicios, bienes, objetos y dispositivos, de modo que sean utilizables por la mayor cantidad de personas posible, sin necesidad que se adapten o especialicen para sectores poblacionales determinados ${ }^{52}$. En este enfoque, la accesibilidad es redefinida como una característica básica de los entornos productos y servicios que posibilita su uso por todas las personas, independientemente de sus atributos corporales y particulares.

Se plantea que el Diseño Universal constituye una evolución, superación y ampliación del Diseño Libre de Barreras ya que objeta su concepción de accesibilidad, poniendo en cuestión sus tres características esenciales, que describimos en páginas precedentes. En ese sentido, el enfoque del Diseño Universal:

a. Afirma la multidimensionalidad de la accesibilidad: Los referentes del Diseño Universal plantean que el diseño utilizable debe extenderse más allá de los edificios que habitamos, o los espacios arquitectónicos en los que nos movemos, sino que debe ser parte de todo lo que usamos. En ese sentido señalan que la accesibilidad presenta múltiples dimensiones: arquitectónica, urbanística, tecnológica, comunicacional, informacional (incluidos los sistemas y las tecnologías de la información y de la comunicación), cultural, recreativa, entre otras ${ }^{53}$.

b. Amplía los destinatarios o usuarios de la accesibilidad: Los defensores del Diseño Libre de Barreras reconocieron la necesidad de un enfoque que aborde los requerimientos de las "personas con y sin discapacidades", tomando conciencia de la implicación que la accesibilidad tiene en la calidad de vida de todas las personas ${ }^{54}$. En ese sentido, el Diseño Universal surge con el objeto de mejorar los entornos, sus instalaciones, productos y servicios, para optimizar el funcionamiento corporal y posibilitar la realización de actividades y la participación social de toda la población. No únicamente de una población predefinida según la edad o la capacidad funcional ${ }^{55}$. En ese sentido, Mace ${ }^{56}$ señala que la intención del concepto de diseño universal es simplificar la vida de todos.

El diseño orientado a una diversidad de usuarios se basa en el reconocimiento de la heterogeneidad corporal, es decir, de las múltiples complejidades y características del cuerpo y de la multiplicidad de formas en que los cuerpos interactúan con los elementos del entorno ${ }^{57}$. De esta manera se postula que los destinatarios de la accesibilidad no son exclusivamente las

51 Mace, Mueller y Story, 1998; Alonzo López, 2007 b; CEAPAT, 2008; Imrie y Gaete Reyes, 2009.

52 Mace, 1988.

53 Alonzo López, 2007 b; Imrie y Gaete Reyes, 2009.

54 Mace, Mueller y Story, 1998; Alonzo López, 2003, 2007 a; Imrie, 2012.

55 Steinfeld, 2006 a, 2006 b.

56 Mace, 1988.

57 Alonzo López, 2007 a; Imrie, 2013. 
personas definidas como discapacitadas, sino toda la población independientemente de sus características singulares.

c. Propone eliminar la segregación y discriminación a través del diseño: En línea con el punto anterior, el Diseño Universal cuestiona la "accesibilidad segregada" del enfoque del Diseño Libre de Barreras y postula una accesibilidad que permita el uso y disfrute de los espacios comunes a todas las personas, sin la creación de espacios diferenciados "especiales" que generan aislamiento y estigmatizan a sus usuarios "especiales"58.

Se plantea que el principio general del Diseño Universal consiste en evitar la discriminación a través del diseño, buscando garantizar la participación plena en la sociedad de las personas catalogadas como discapacitadas ${ }^{59}$.

Por otro lado, otro aporte del Diseño Universal es que subraya la necesidad de no centrarse únicamente en la supresión de las barreras existentes, sino de incorporar la accesibilidad desde el origen del diseño y la planificación de los entornos, productos y servicios. Las características de accesibilidad deben ser intrínsecas al diseño, de esta manera se convierten en parte del "todo" y no en un agregado cuando se termina el proyecto ${ }^{60}$. En ese marco, sus referentes argumentan que la concepción de accesibilidad del enfoque de Diseño Libre de Barreras es restrictiva y limitada.

En base a lo antes señalado, se puede plantear que uno de los principales aportes del paradigma del Diseño Universal es su promoción y defensa del uso equitativo de entornos, productos y servicios, y del desarrollo de un diseño que no presente desventajas para algún grupo de usuarios ${ }^{61}$. En ese sentido, este enfoque se fundamenta en el reconocimiento de que el diseño de los entornos construidos -ya sean físicos o virtuales- puede crear limitaciones en la actividad y en la participación de muchas personas, incluso en aquellas que no son definidas como discapacitadas. Estos entornos a menudo presentan elementos que pueden ser inutilizables por algunos miembros de la población con lo cual se infringe su libertad o su derecho "a tener acceso a" o "a hacer uso de"62.

Pese a sus contribuciones a la ampliación y re-significación del concepto de accesibilidad, el Diseño Universal no ha estado exento de críticas y se le han atribuido varias limitaciones. Entre las principales se destacan:

- Supone una amplia aceptabilidad del diseño por parte de todas las personas, omitiendo aquellos problemas relacionados con la compatibilidad y la implementación en contextos culturales, sociales y económicos diversos ${ }^{63}$, como en poblaciones heterogéneas.

Quizás en su versión más "ortodoxa"64 el Diseño Universal postula que existe una única solución universalmente aceptable para todos los problemas de diseño. Según sus adeptos, este objetivo puede conseguirse integrando las distintas necesidades de las personas en una solución útil para todos ${ }^{65}$. Se plantea que esta afirmación es a la vez utópica y simplista. A su vez es inalcanzable debido a las divisiones étnicas y culturales dentro y fuera de los estadosnación, así como las diversas necesidades al interior de los diferentes grupos específicos de personas ${ }^{66}$. El ideal de encontrar una "solución única" que responda a distintos requerimientos

58 Steinfeld, 2006 b.

59 Rodríguez-Porrero, 2002; CEAPAT, 2008; Imrie y Gaete Reyes, 2009; Barnes, 2011; Imrie, 2012.

60 Mace, Mueller y Story, 1998; Alonzo López, 2007 b; CEAPAT, 2008; Imrie y Gaete Reyes, 2009 ; Imrie, 2012.

61 Imrie, 2014.

62 Steinfeld, 2010; Imrie y Gaete Reyes, 2009; Imrie, 2012, 2013

63 Barnes, 2011.

64 Imrie, 2012.

65 CEAPAT, 1996; Steinfeld, 2006 a.

66 Barnes, 2011. 
parece fundamentarse en la lógica de la estandarización del diseño, lo cual puede ser contradictorio con el reconocimiento de la heterogeneidad humana. En este sentido Imrie ${ }^{67}$ señala que "no es posible crear un producto que pueda ser usado por todo el mundo o en todas las circunstancias. Esto encierra el pensamiento, quizás utópico, de que se pueden lograr soluciones de diseño que responden a todas las necesidades".

Considera que las tecnologías de apoyo pueden ser prescindibles o incluso innecesarias.

En estrecha vinculación con el punto anterior, el Diseño Universal ortodoxo se basa en proporcionar elementos de diseño que no requieran el uso de técnicas y tecnologías de apoyo o equipos especializados. Esto podría no funcionar o no ser factible en todos los casos, porque hay algunas personas que por su configuración corporal pueden requerir asistencia 0 características de diseño especializado ${ }^{68}$.

Las "tecnologías de apoyo", "ayudas técnicas" o más recientemente "productos de apoyo"69, son aquellos recursos, herramientas, dispositivos o instrumentos fabricados específicamente en base a las posibilidades funcionales y características de una persona particular en una situación determinada. Representan apoyos imprescindibles para favorecer la movilidad, la comunicación, el desarrollo de actividades de la vida diaria, el acceso al conocimiento y a la información en personas con alguna limitación en la actividad o restricciones en la participación ${ }^{70}$. La utilización de estos dispositivos se orienta a obtener la mayor autonomía posible en esta población durante el desarrollo de diferentes actividades, y a garantizar el derecho humano a la autodeterminación.

En este sentido, parece prematuro y desatinado que el movimiento del Diseño Universal reaccione contra las características específicas o especializadas del diseño ${ }^{71}$. No obstante, formulaciones más recientes de este enfoque postulan la necesaria complementariedad y compatibilidad con las ayudas técnicas ${ }^{72}$. Así, Steinfeld ${ }^{73}$ indica que "siempre habrá necesidad de tecnologías de asistencia y servicios especializados, por lo tanto, aunque el Diseño Universal podría reducir su necesidad, no va a eliminarlas por completo".

- $\quad$ Promueve la mercantilización del acceso.

El Diseño Universal se caracteriza por la defensa de la mercantilización y la comercialización del acceso como el medio principal para garantizar la accesibilidad en los productos, incluido el entorno construido. Esto tiene el potencial de reducir el "derecho a acceder" a un derecho que se ejerce a través de un intercambio en el mercado, en virtud de una transacción comercial y de la capacidad del individuo para pagar por un bien y/o servicio accesible ${ }^{74}$. A su vez refuerza el status de "meras mercancías" de los entornos, sus instalaciones, así como de los productos y servicios. En ese sentido, la adopción y propagación de discursos de mercado parece ser la base del diseño de productos y del desarrollo de entornos.

La lectura de algunos textos de Ronald Mace, referente e impulsor de esta perspectiva, permite identificar su preocupación por las posibilidades de comercialización de los productos y dispositivos de Diseño Universal. De este modo, pone el énfasis en su atractivo, facilidad de uso y potencial consumo masivo:

\section{Imrie, 2013.}

68 Imrie y Gaete Reyes, 2009.

69 International Organization for Standardization, ISO 9999:2007, ISO 9999:2011.

70 International Organization for Standardization, ISO 9999:2011; Mace, 1998.

71 Imrie y Gaete Reyes, 2009.

72 Alonzo López, 2002; Aragall, 2002; Steinfeld, 2006 a, 2006 b; CEAPAT, 2008; Imrie, 2013

73 Steinfeld, 2010.

74 Imrie y Gaete Reyes, 2009; Imrie, 2012, 2013. 
El diseño universal en términos generales lo define el usuario, es un tema impulsado por el mercado de consumo. Implica diseñar el medio ambiente construido y los productos de consumo para una amplia gama de usuarios, que fomenta productos atractivos y comercializables que sean más utilizables por todos.

Es un salto revolucionario y práctico en la evolución de los procedimientos de construcción y diseño. Cuando los diseñadores y fabricantes aprovechan este concepto, el diseño universal se convertirá en habitual, cómodo y rentable ${ }^{75}$.

Esta promoción de la comercialización del acceso parece muy alejada de algunos de los tempranos ideales de los movimientos de defensa de los derechos civiles de la década de $1960^{76}$

- Presenta una excesiva confianza en la tecnología.

El enfoque del Diseño Universal focaliza, principalmente, en el desarrollo, aplicación y evaluación de tecnologías y técnicas para asegurar que los ambientes sean accesibles. En ese sentido, se caracteriza por exponer un discurso técnico que promueve debatir acerca de los métodos y técnicas del diseño. Éste asume una relación directa, incluso causal, entre las características del diseño y la creación de espacios accesibles ${ }^{77}$.

Algunos autores han cuestionado este discurso, planteando que se basa en "una creencia generalizada y acrítica de los beneficios de la tecnología y la innovación técnica para garantizar un diseño accesible". Se plantea que este enfoque crea expectativas poco razonables de lo que la tecnología puede ofrecer, considerando a las intervenciones tecnológicas como superiores, y que sólo podrían ser mejoradas a través de la utilización de más y mejores tecnologías ${ }^{78}$.

De esta manera, el Diseño Universal sería parte de un "paradigma de resolución de problemas", que omite el componente político del fenómeno de la accesibilidad. Es decir, tiende a presentar las injusticias de un ambiente mal diseñado e inaccesible más como resultado de la aplicación de tecnologías de diseño inadecuadas, que como una cuestión socio-política en la que concurren y entran en conflicto normas, valores y pautas de convivencia ${ }^{79}$.

Considerando los aportes y limitaciones del Diseño Universal para re-interpretar la accesibilidad, parece oportuno repensar a este paradigma como una aspiración a alcanzar y no como un "estado o condición absoluta"80. Lejos de considerarlo como la panacea para los problemas de inaccesibilidad en entornos, productos y servicios, se estima importante interpretarlo como una perspectiva en construcción y debate permanente respecto a los modelos de perfección corporal y normalidad humana establecidos en las disciplinas del diseño, incorporando las diversas funcionalidades, habilidades y potencialidades humanas, $y$ reconociendo los ilimitados y heterogéneos modos de comportarse, moverse y usar los espacios $^{81}$.

Parece importante, además, afirmar su compatibilidad con las tecnologías de apoyo. En ese sentido, el desarrollo de productos de apoyo específicos para personas catalogadas como discapacitadas y el desarrollo de condiciones de accesibilidad en los entornos urbanos, edilicios y comunicacionales desde el paradigma del Diseño Universal, constituyen dos estrategias

75 Mace, 1988, 1998.

76 Imrie y Gaete Reyes, 2009.

77 Imrie, 2013.

78 Ibíd.; Imrie y Gaete Reyes, 2009; Imrie, 2012.

79 Ibíd.

80 Steinfeld, 2006 b; 2010.

81 Nos remitimos al planteo de Silvia Coriat (2012) respecto a la necesidad de "problematizar la lógica del uso de los espacios". 
complementarias que tienen como objetivo favorecer la inclusión y la participación en todas las esferas de la sociedad ${ }^{82}$. Si bien algunos sectores de la población pueden poseer productos de apoyo específicos que favorecen su autonomía y la autodeterminación, cabe destacar que es condición necesaria que los entornos urbanos, edilicios y comunicacionales de las universidades sean accesibles para que la inclusión educativa sea efectiva e integral.

En este marco, y desde una perspectiva de derechos humanos, el Protocolo concibe la accesibilidad como aquella cualidad fundamental que deben cumplir los espacios, ámbitos, servicios, bienes, así como los objetos o instrumentos, herramientas y dispositivos, para poder ser utilizables por todas las personas de manera: autónoma, es decir, en forma independiente, no subordinada al auxilio de otra; segura, o sea, libre de todo peligro o riesgo; confortable, es decir, de manera cómoda sin inconvenientes, obstáculos o restricciones en su uso, y con un mínimo de esfuerzo; y equitativa, es decir, con equidad entendida como la cualidad que consiste en atribuir a cada persona aquello que le corresponde por derecho.

La accesibilidad constituye una "característica básica de los entornos construidos" (sean estos reales o virtuales), que determina las posibilidades de uso de todo lo que estos ofrezcan o presenten ${ }^{83}$.

Así entendida, la accesibilidad presenta algunas características que adquieren trascendencia en los procesos de gestión de políticas educativas de nivel superior.

En primer lugar, es una condición de posibilidad para el ejercicio pleno y efectivo de derechos fundamentales por parte de todas las personas, como el derecho a la educación superior de carácter público, sin ningún tipo de discriminación. Y otros derechos como el derecho de circulación y tránsito autónomo y seguro, de comunicación, de acceso autónomo y oportuno a la información y al conocimiento, en síntesis, de participación en los circuitos de producción, intercambio y consumo de bienes y servicios, tanto materiales, virtuales, como simbólicos, de las instituciones de educación superior. En definitiva, de apropiación de los espacios y actividades públicas y sociales. En este sentido, constituye una cuestión de derechos humanos.

En coherencia con lo antes señalado, constituye el requerimiento elemental para alcanzar grados crecientes de inclusión educativa, sin discriminaciones de ninguna índole. Si la inclusión educativa es entendida como: "El conjunto de acciones tendientes a favorecer la participación en las actividades académicas, y a promover el uso efectivo y disfrute de los bienes y servicios educativos y de aquellos que complementan los procesos de enseñanza-aprendizaje" ${ }^{24}$, se advierte que la accesibilidad es fundamental para alcanzar esta aspiración que apunta a hacer efectivo el involucramiento de todas las personas, no solo en la vida académica de las instituciones de educación superior, sino también, en la vida institucional.

Por lo tanto, la accesibilidad se erige como el eje transversal de las políticas de educación superior orientadas a la inclusión educativa. De esta manera, diremos que transversalizar la perspectiva de la accesibilidad en el diseño y formación de políticas de educación superior, constituye la condición necesaria para el establecimiento de instituciones inclusivas y, por sobre todo, respetuosas de la heterogeneidad inherente al ser humano, en las que todas las personas, independientemente de sus características singulares (bio-físicas, lingüísticas, étnicas, entre otras) ejerzan el derecho a participar e integrarse en sus espacios, ya sean estos materiales o virtuales. De este modo, la transversalización de la perspectiva de la accesibilidad es quizás uno de los desafíos medulares de las instituciones de educación superior en el siglo

82 García Alonzo, 2003.

83 CEAPAT, 1996.

84 Mareño Sempertegui, 2008. 
XXI, si es que pretenden revertir inequidades profundas e invisibles y construir instituciones menos excluyentes.

\section{Características centrales del proceso de gestión del Protocolo: interdisciplinariedad y producción multiactoral.}

Con el objetivo de elaborar el Protocolo de Accesibilidad Urbana y Edilicia, desde la Secretaría de Asuntos Estudiantiles, a través de la OIE, y la Subsecretaría de Planeamiento Físico de la Secretaría de Planificación y Gestión Institucional de la UNC, se desarrolló una estrategia institucional de gestión asociada, que presentó como componentes centrales: la interdisciplinariedad y la producción multiactoral.

De esta manera, entre los meses de mayo y junio del año 2012 se organizó un espacio de trabajo y producción colectiva, en el marco de lo solicitado a ambas dependencias en la Resolución No 478/11 del Honorable Consejo Superior.

Este espacio denominado "Jornadas de Diseño Universal: hacia la elaboración de un Protocolo de Pautas de Accesibilidad en espacios urbanos y edilicios de la UNC", estuvo destinado a directivos y profesionales de los equipos técnicos de la Subsecretaría de Planeamiento Físico, y a profesionales de los equipos técnicos de las áreas de Infraestructura, Planeamiento, Higiene y Seguridad de las dependencias y unidades académicas de la universidad.

Se propuso tres objetivos estrechamente vinculados entre sí e interdependientes, a saber, propiciar el conocimiento del paradigma del Diseño Universal y la reflexión sobre su centralidad para la generación de instituciones educativas menos excluyentes; difundir la importancia de la incorporación de los principios de este paradigma en el diseño, construcción y producción de espacios urbanos y edilicios de la UNC, para que sean utilizables por todas las personas de manera autónoma y segura; y elaborar de manera participativa un Protocolo de Pautas de Accesibilidad que oriente el diseño y construcción de esos espacios.

En coherencia con lo señalado al inicio de este apartado, las Jornadas se basaron en dos principios fundamentales: el principio de la interdisciplinariedad y el principio de la producción participativa.

El principio de la interdisciplinariedad plantea el necesario diálogo y articulación de una pluralidad de disciplinas y perspectivas al abordar fenómenos complejos y por ende multidimensionales, como el de la accesibilidad. Franqueando así las "fronteras disciplinarias"85, que tradicionalmente han generado abordajes mono-disciplinares respecto a determinadas problemáticas, que parcelan, segmentan y limitan su comprensión.

A su vez, promover la participación de los profesionales de las áreas de Infraestructura, Planeamiento, Higiene y Seguridad de la UNC, se fundamentó en la necesidad de resignificar los procesos de producción y diseño de propuestas de intervención en las instituciones de educación superior, tendiendo a propiciar el involucramiento activo de los actores institucionales responsables de la proyección, construcción y refacción de los espacios universitarios, tanto urbanos como edilicios.

Este carácter participativo e interdisciplinar de las Jornadas contribuyó al trabajo en subgrupos por parte de los participantes, y la posterior puesta en común de lo trabajado en instancia de plenario. La socialización de las producciones grupales y la discusión de las problemáticas de inaccesibilidad reconocidas como prioritarias, orientó la definición colectiva de las pautas que conformarían el Protocolo de Accesibilidad.

85 Morin, 2007. 


\section{El Protocolo. ¿Qué es? ¿Cómo se organiza y cuáles son sus componentes?}

El Protocolo de accesibilidad urbana y edilicia constituye un documento institucional que comprende un conjunto de pautas y recomendaciones, que deberán aplicarse en el ámbito de la UNC, al momento de proyectar, ejecutar, ampliar, modificar y redefinir nuevos espacios urbanos y edilicios propios de las actividades que se realizan en la universidad, ya sean estas académicas, culturales, recreativas, deportivas, administrativas, etc.

Tiene como objetivo primordial la supresión de barreras urbanas, arquitectónicas y comunicacionales. Es decir, todo tipo de obstáculos, impedimentos, obstrucciones que limitan la realización de actividades y restringen la participación, el uso y la apropiación de los espacios, ámbitos, instalaciones, bienes y servicios educativos de la universidad, por parte de todas las personas implicadas en los procesos de enseñanza-aprendizaje, independientemente de sus características particulares. Estas barreras, constituyen barreras institucionales en tanto son producto de las modalidades tradicionales a partir de las cuales se diseñaron, planificaron y construyeron los espacios de la UNC.

En ese sentido, supone un marco referencial, es decir, un marco conceptual que pretende fundamentar el diseño y la planificación, como así también, establecer y unificar criterios de accesibilidad, seguridad, medio ambiente y comunicación para la construcción de espacios urbanos y edilicios de la UNC. Un marco que justifica las decisiones a tomar y las intervenciones a implementar.

Constituye, además, una herramienta de gestión del espacio público de la UNC, es decir, una guía, un instrumento de uso y consulta permanente por parte de los equipos de las áreas de planeamiento, infraestructura, medio ambiente, higiene y seguridad, que orientará la planificación, el diseño y la construcción del espacio urbano y edilicio de la universidad.

Las pautas que conforman el Protocolo, no constituyen un corpus acabado, por lo que pueden complementarse y enriquecerse, con otras prescripciones surgidas de la práctica y/o la creatividad puestas en juego en el proceso de diseño del espacio universitario. En este sentido, podrá, eventualmente, adaptarse a las particularidades de cada requerimiento o situación, respetando siempre los criterios de universalidad en los que se cimienta.

Cabe señalar el carácter complementario de las pautas, es decir, no presentan un orden de jerarquía y ninguna de ellas garantiza de manera absoluta la accesibilidad urbana y edilicia. Su mayor potencial radica en su articulación y sinergia según cada situación particular.

Las pautas de accesibilidad que conforman el Protocolo se organizan en cuatro ejes que contemplan las dimensiones del espacio urbano del predio de Ciudad Universitaria y de los edificios de la UNC. Esta clasificación en cuatro ejes, y las respectivas dimensiones que los conforman, constituye una adaptación del Instructivo y de las Planillas de Relevamiento del "Programa de Accesibilidad en Universidades Nacionales" de la Secretaría de Políticas Universitarias del Ministerio de Educación de la Nación".

A continuación se presenta el esquema en el que se organizan las pautas del Protocolo, según sus cuatro ejes principales y sus respectivas dimensiones:

\section{EJE I: ENTORNO, CAMPUS UNIVERSITARIO}

Dimensiones:

1. Itinerarios Peatonales: senderos, veredas, cruces peatonales (vados).

2. Mobiliario Urbano: bebederos, papeleras, bancos, mojones, teléfonos públicos. 
3. Señales verticales: señales de tránsito, semáforos, luminarias, elementos verticales de señalización, (paneles de información), señalización externa.

4. Paradas de colectivos.

5. Estacionamientos.

\section{EJE II: ARQUITECTONICO: EDIFICIOS UNC}

Dimensiones:

1. Exterior: zona de aproximación del edificio.

2. Acceso: zona de transición entre exterior e interior.

3. Interior: Circulaciones Horizontales (Hall de ingresos y Circulación o Paso)

4. Interior: Circulaciones Verticales (Escaleras, Rampas, Ascensores).

\section{EJE III: ESPACIOS DE USO}

Dimensiones:

1. Bibliotecas: zona exterior, acceso, hall de ingreso, circulación o paso, zona de guardado, zona de consulta previa, zona de devolución, zona de préstamo, zona de lectura, zona de almacenaje de libros.

2. Auditorios: Circulaciones Horizontales (Hall de ingresos y Circulación o Paso), escenarios, butacas.

3. Aulas - Aulas Talleres: mobiliario, pizarrón.

4. Aulas de informática: mobiliario, computadoras personales y accesorios, dispositivos tecnológicos de apoyo.

5. Laboratorios: mobiliario, puestos de trabajo.

6. Administración: mobiliario, zona de espera de público, zona de atención al público, zona de archivos.

7. Comedor - Cantinas: zona exterior, acceso, circulaciones horizontales, mobiliario, zona de permanencia, zona de atención.

8. Sanitarios: circulaciones horizontales, mobiliario, accesorios.

\section{EJE IV: SEÑALIZACIÓN, SEÑALÉTICA y PANELES INFORMATIVOS}

Dimensiones:

1. Materialización.

2. Localización.

Cabe señalar que a cada una de las dimensiones que conforman los ejes, le corresponden una serie de pautas de accesibilidad, elaboradas en función de las características y particularidades del predio y los edificios de la UNC.

Por otro lado, en la construcción de las pautas se contemplaron las condiciones de seguridad, ya que consideramos que la accesibilidad y la seguridad constituyen dos fenómenos inherentes, que deben ser constitutivos de los espacios urbanos y edilicios de las universidades.

La normativa vigente en nuestro país en cuanto a accesibilidad, a saber, la Ley Nacional No 24.314 de "Accesibilidad al Medio Físico" y su Decreto Reglamentario No 914, constituyó el punto de partida para la elaboración de las pautas que conforman el Protocolo. No obstante, fue revisada críticamente planteando la redefinición de las actuaciones que se deberían desarrollar para alcanzar la aplicación de los criterios del Diseño Universal. Por ejemplo:

- Un campus universitario donde todas las personas se desplacen y se orienten con facilidad, a través de itinerarios peatonales accesibles, diseñados de manera que sean transitables y seguros. 


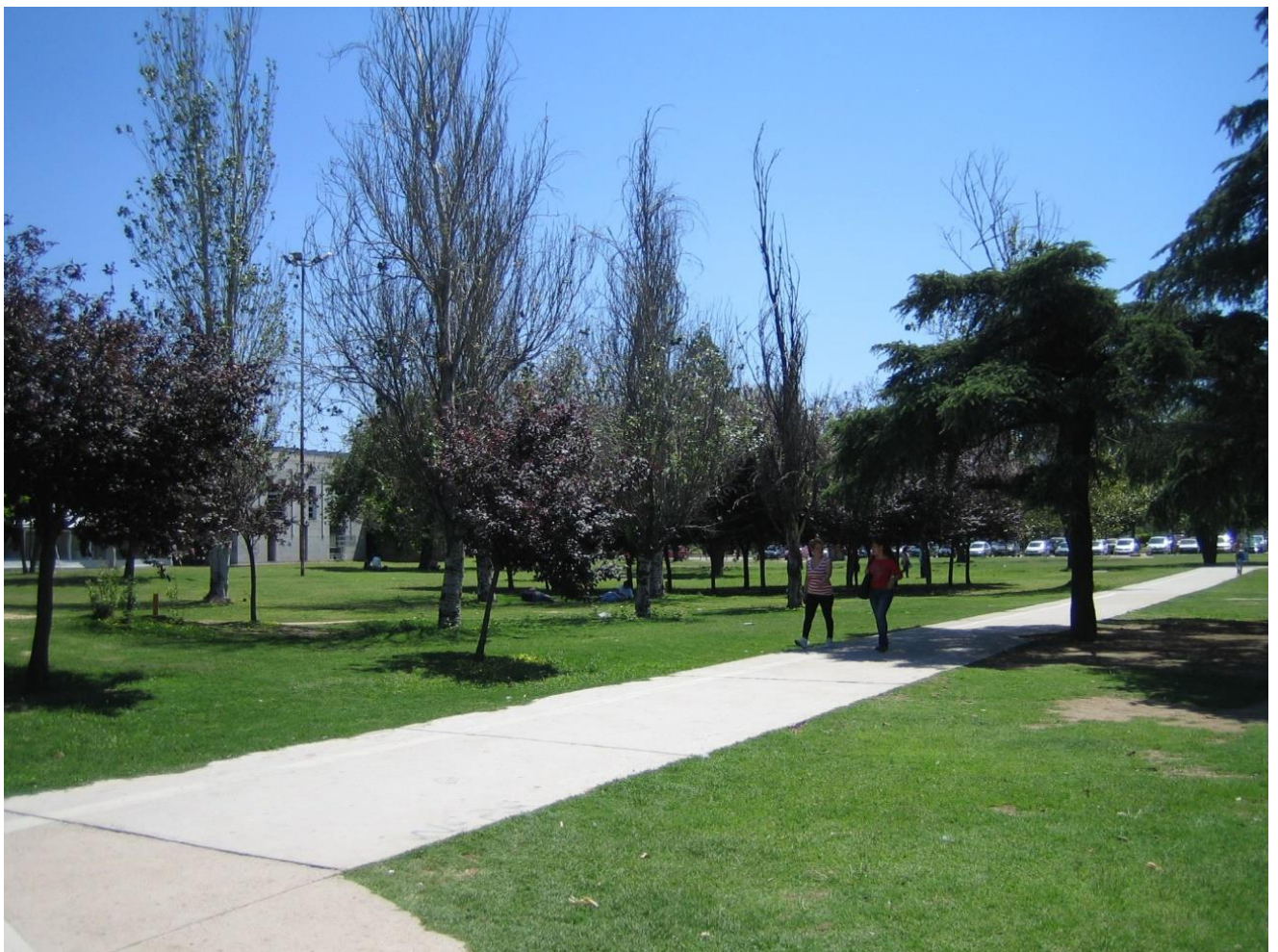

Fig. 1 Itinerario peatonal en Ciudad Universitaria. Universidad Nacional de Córdoba. Fte: Elaboración propia

Veredas exteriores y senderos interiores, teniendo en cuenta el flujo peatonal previsto considerando un volumen sin riesgo, por donde podrán circular dos personas de forma simultánea, ambas usuarias de silla de ruedas (2,50 m como mínimo), ampliando así, el ancho mínimo de 1,50 m de las normativas vigentes (Fig. 2).

Se proponen distintas alternativas en cuanto a la localización de zonas de descanso. En las veredas exteriores se situarán paralelo a la zona de circulación libre de obstáculos, y según la categoría de la calzada. Se optará por una ubicación próxima a la calle, donde podrá alinearse el mobiliario urbano, las señales verticales, el arbolado, y las paradas de colectivos (en el sentido longitudinal al itinerario peatonal) o se escogerá la zona próxima a la calles sólo para colocar el arbolado y señales verticales mientras que las aéreas estanciales con mobiliario urbano se ubicarán en el otro extremo, es decir, el lado interior de la circulación. En los senderos interiores se localizarán a distancias adecuadas, como apoyo al itinerario peatonal. El mobiliario, las luminarias y cualquier elemento de señalización se ubicarán fuera de la zona de circulación.

- Se plantea la necesidad de repensar la materialidad de veredas exteriores y senderos interiores, utilizando pavimentos regulares, sin resaltos, antideslizantes, como contempla la normativa, pero se avanza en cuanto a la determinación de algunos criterios de manera más concreta. Se prevé cuestiones de mantenimiento, la ejecución de juntas, bordes, superficie de material, de modo de posibilitar su uso y el menor esfuerzo, a la mayor cantidad de personas. Se considera la utilización de tres a cuatro solados diferentes como máximo en todo el campus. Se incorpora la diferenciación de textura y color del material del solado creando recorridos, para que guíe y oriente a personas con baja visión o con ceguera. Se emplean bandas podo táctiles de color resaltante, o la ejecución de un cordón de hormigón, según los casos (Fig. 3). 


\section{REVISTA DE \\ URBANISMO}

ISSN 0717-5051

http://revistaurbanismo.uchile.cl
Revista de Urbanismo N³0 - Enero - Junio de 2014 Departamento de Urbanismo - FAU - Universidad de Chile

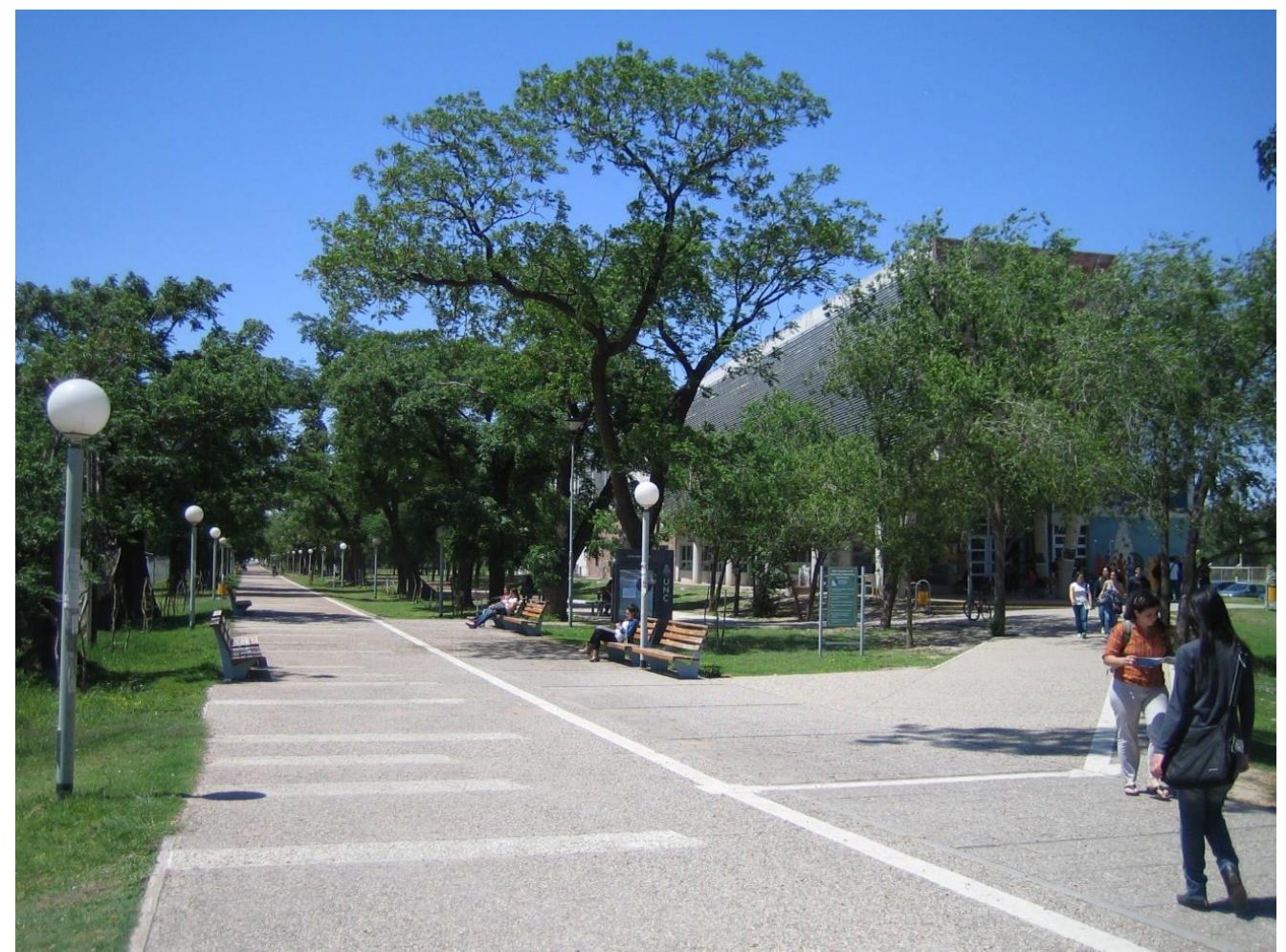

Fig. 2 Itinerario peatonal y mobiliario urbano en Ciudad Universitaria. Universidad Nacional de Córdoba. Fte: Elaboración propia

Diseño de elementos de señalización como el mobiliario urbano, las luminarias y los paneles de información, según los principios de diseño universal en pos de permitir su uso, de manera autónoma, a la mayor cantidad posible de personas. Su ubicación será fuera de la zona de circulación.

- Se evitarán los desniveles en los entornos inmediatos de edificios nuevos. Se podrá llegar a estos desde las playas de estacionamiento y/o las paradas de transporte público de pasajeros, a través de un itinerario accesible.

- Se podrán resolver accesos a través de recorridos exteriores con escasa pendiente $(<4 \%)$.

- Los accesos tendrán el mismo nivel de piso que el exterior (desnivel $\leq 1 \mathrm{~cm}$ ), evitando generar escalones aislados. La normativa actual contempla como altura máxima de umbral: $2 \mathrm{~cm}$. 


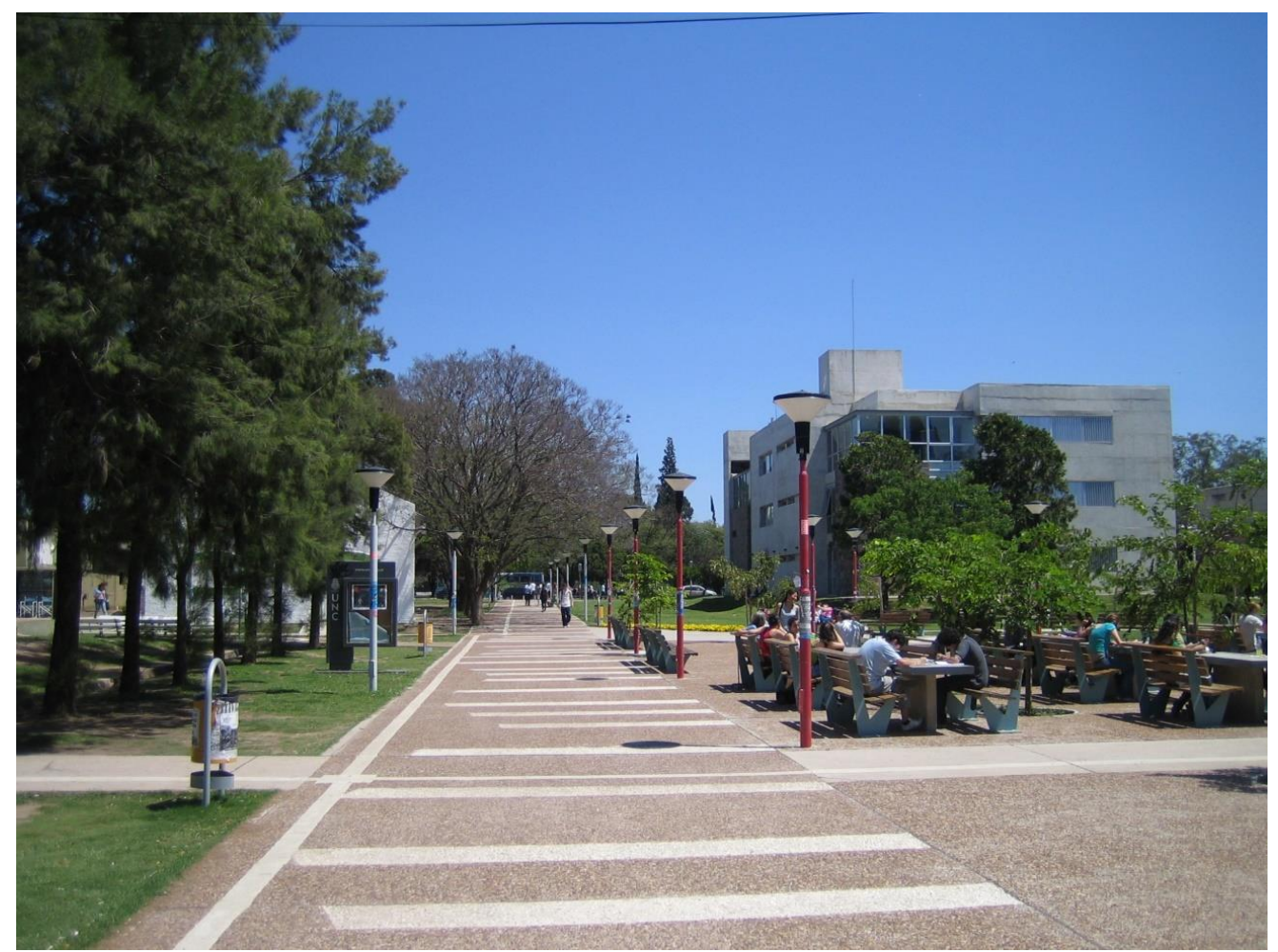

Fig. 3 Itinerario peatonal y mobiliario urbano en Ciudad Universitaria. Universidad Nacional de Córdoba. Fte: Elaboración propia

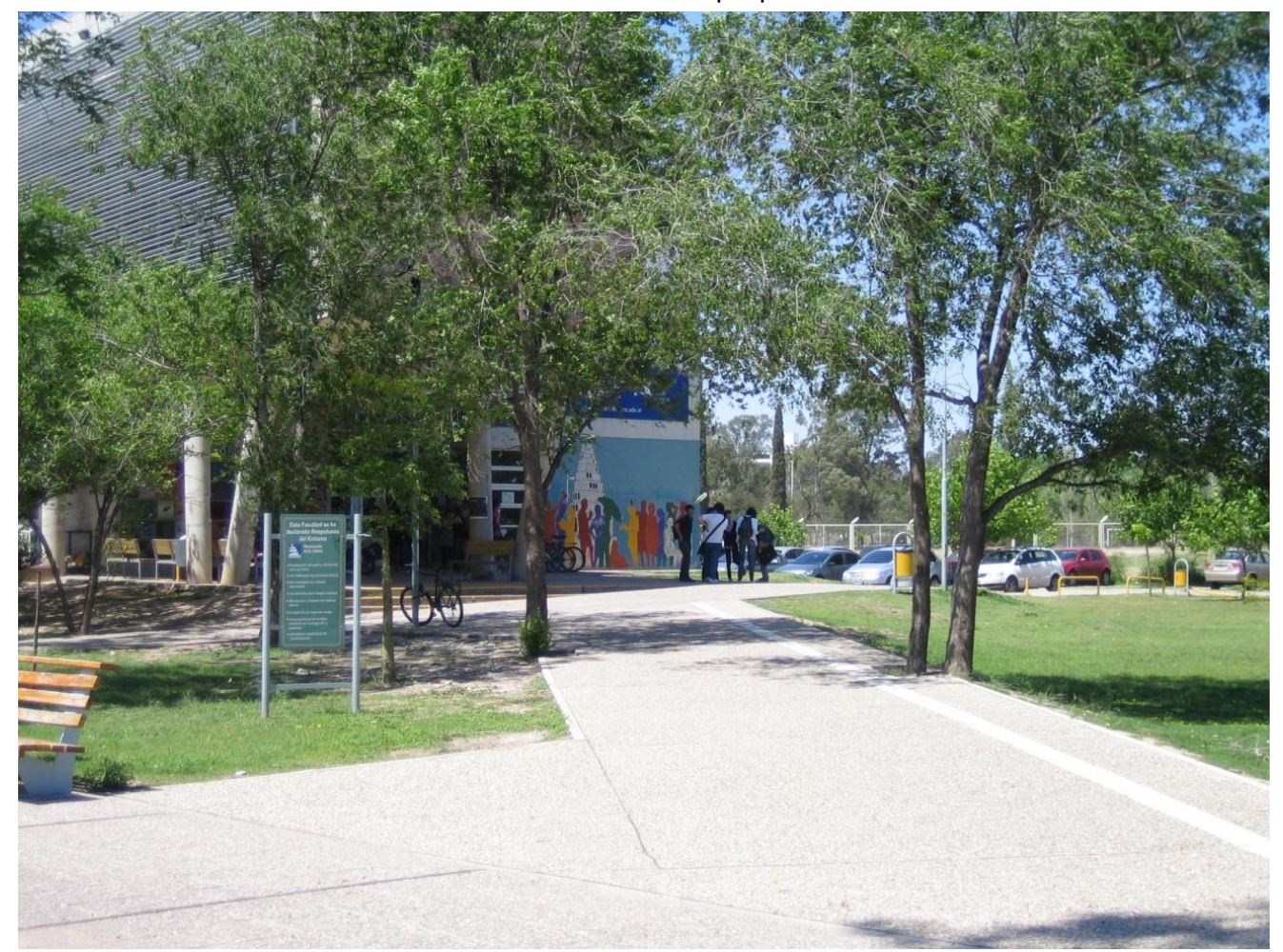

Fig. 4 Acceso a edificio de la Facultad de Lenguas. Ciudad Universitaria. Universidad Nacional de Córdoba. Fte: Elaboración propia 


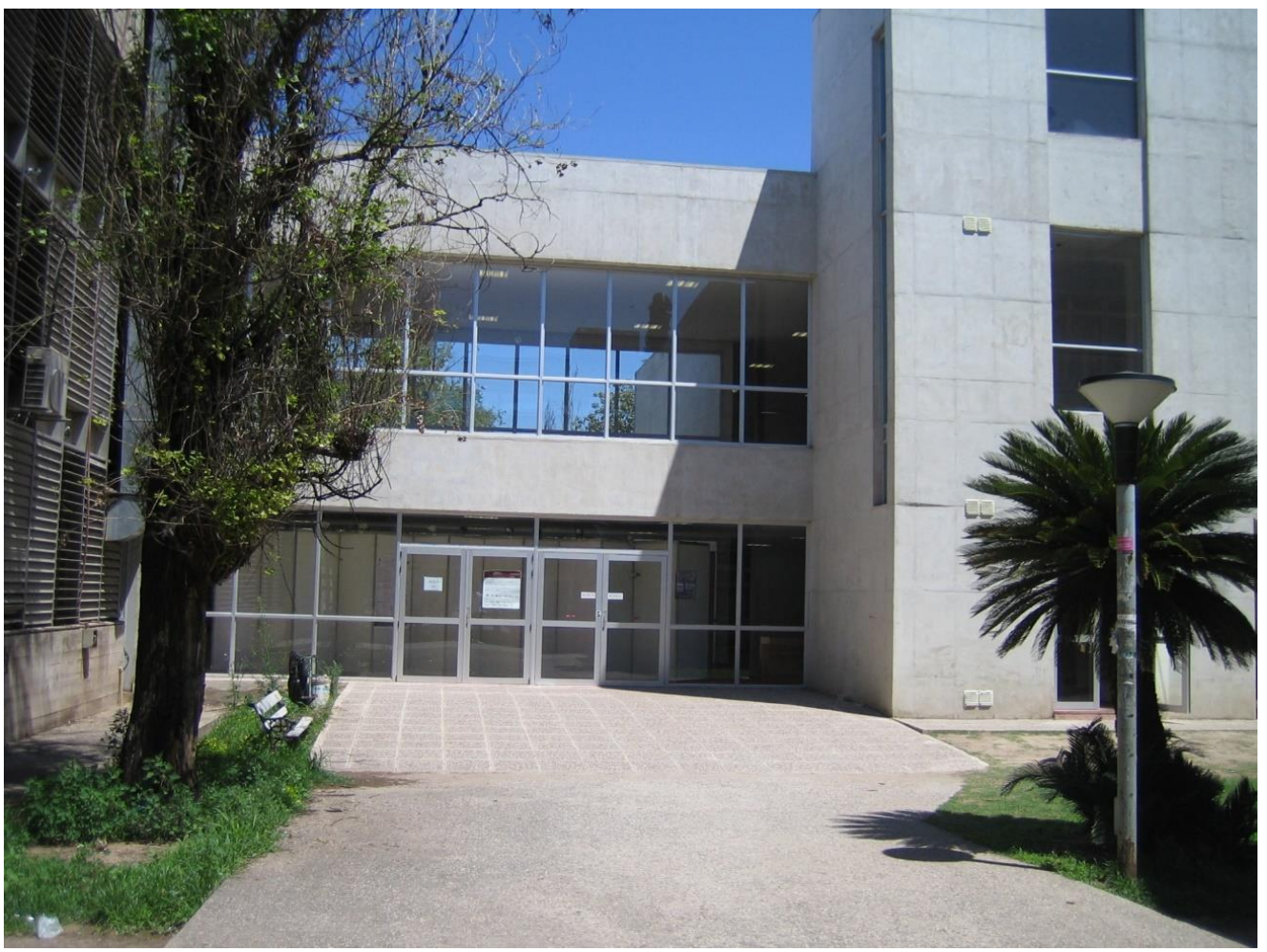

Fig. 5 Acceso a edificio de la Facultad de Ciencias Económicas. Ciudad Universitaria. Universidad Nacional de Córdoba.

Fte: Elaboración propia

\section{Algunas conclusiones}

Este artículo intentó comunicar sucintamente los aspectos más relevantes del proceso de gestión del Protocolo de Accesibilidad Urbana y Edilicia de la UNC.

Repasamos su contexto de surgimiento, la perspectiva conceptual que lo fundamenta y los principios transversales de su proceso de gestión: la interdisciplinariedad y la producción multiactoral. Finalmente, presentamos los ejes y dimensiones en los que se organizan las pautas de accesibilidad que lo componen.

Se expuso que el Protocolo se cimenta en una estructura conceptual que pretende superar concepciones tradicionales que aún prevalecen en las políticas de accesibilidad de las universidades de la región, y que resultan insuficientes para orientar el diseño de intervenciones respetuosas de derechos fundamentales. En ese sentido, propone resignificar los conceptos de discapacidad y accesibilidad desde un enfoque de derechos.

El enfoque de derechos ${ }^{86}$ en tanto marco conceptual y de acción para ser utilizado en el ámbito del diseño e implementación de políticas de educación superior, reconoce que las personas catalogadas como discapacitadas no son víctimas a compensar o "un grupo especial que requiere de atención especial", sino sujetos portadores de derechos, lo cual supone obligaciones para los Estados y sus instituciones. Estas obligaciones de traducirán en medidas de política universitaria orientadas a garantizar el ejercicio pleno del derecho a acceder y transitar de manera autónoma y segura por sus entornos urbanos y edificaciones, a la comunicación efectiva, a acceder a la información y al conocimiento de manera oportuna, a

86 Abramovich, 2006. 
participar en actividades y espacios académicos, recreativos, deportivos, culturales, etc. En síntesis, a garantizar el derecho a la educación superior, sin discriminaciones de ninguna índole.

Este enfoque a su vez, establece no solo aquello que el Estado no debe hacer, a fin de evitar la vulneración de derechos, sino también aquello que debe hacer en pos de lograr la vigencia efectiva de derechos reconocidos en tratados y pactos internacionales ${ }^{87}$.

En este marco, se planteó que el Protocolo trasciende la noción de discapacidad entendida como tragedia biológica individual, que impide la participación social de sus "portadores", quienes, a su vez, dependen exclusivamente de la rehabilitación médica y la asistencia social para poder insertarse en las esferas de la sociedad. Concepción inscripta en el denominado "modelo individual de la discapacidad". En las antípodas, su concepto de discapacidad pone el énfasis en la sistemática vulneración de derechos fundamentales que padecen algunas categorías de personas, debido a las limitaciones que les imponen las modalidades de diseño y construcción del entorno, basadas en parámetros de normalidad. En ese sentido postula que la discapacidad es una situación construida social y culturalmente. El diseño que no reconoce la heterogeneidad inherente al ser humano y se basa en un prototipo de hombre concebido como "normal", en el denominado "hombre promedio" que constituye una abstracción teórica que en realidad no existe, es un diseño discapacitante.

En esa línea el Protocolo también re-significa la accesibilidad desde el paradigma del Diseño Universal, superando su concepción unidimensional que la interpreta como sinónimo de supresión de barreras arquitectónicas y en el transporte para beneficio exclusivo de aquellas personas catalogadas como discapacitadas.

Como señala Alonso ${ }^{88}$, esta noción de accesibilidad inscripta en el paradigma del Diseño Libre de Barreras, no es incorrecta, es necesaria pero limitada ya que, como se expuso, se centra solo en la supresión de obstáculos.

En este sentido, parece oportuno que en el contexto actual de inaccesibilidad urbana y edilicia en gran parte de las universidades de la región, las políticas para abordar esta problemática supongan la complementariedad de: la eliminación de las barreras existentes y la incorporación de la accesibilidad desde el origen del diseño de todo entorno, edificación, servicio o equipamiento, para que puedan ser utilizados por todas las personas. La combinación de ambas estrategias se revela como necesaria en la coyuntura actual.

Por otro lado, si bien el Protocolo afirma que la accesibilidad desde el paradigma del Diseño Universal contribuye a la mejora de la calidad de vida de todas las personas, reconoce que existen grupos poblacionales más propensos a padecer la existencia de barreras, entre ellos las personas nominadas como discapacitadas. Como plantea Alonso ${ }^{89}$, estos grupos poblacionales se verán más afectados en sus posibilidades de movilidad, comunicación y comprensión, es decir, en su calidad de vida y en su facultad de ejercer plenamente sus derechos fundamentales. En ese sentido, las pautas del Protocolo constituyen verdaderas condiciones ineludibles para garantizar el acceso, la circulación y la apropiación de los espacios, por parte de esta población, en condiciones equitativas. Allí radica su gran importancia.

Consideramos que el proceso transitado por la UNC ha sido muy importante. Que la universidad cuente con un dispositivo institucional para la gestión de un espacio urbano y edilicio accesible y seguro para todas las personas, es auspicioso. Lo es también el hecho de que su diseño y elaboración haya sido de carácter participativo e interdisciplinario, superando los enfoques

87 Pautassi y Gamallo, 2012.

88 Alonso, 2003, 2007a.

89 Alonso, 2003. 
tradicionales de naturaleza mono-disciplinar que durante varias décadas -y aún en la actualidad-, prevalecieron en los abordajes de problemáticas complejas como la inaccesibilidad urbana y edilicia en las instituciones educativas de nivel universitario. Este proceso se enmarca, por supuesto, en un proceso mayor de transformaciones que viene implementando la UNC en los últimos años, orientado a consolidar la democratización del conocimiento como materia prioritaria de política universitaria.

No obstante lo antes señalado, entendemos que apenas nos acercamos al preludio de este proceso. Nos enfrentamos ante el desafío de garantizar la aplicabilidad y el uso del Protocolo. En ese sentido, proponemos generar algunas condiciones institucionales para aproximarnos a ese objetivo. Condiciones estrechamente articuladas entre sí y complementarias:

a. Presentar el Protocolo al Honorable Consejo Superior de la UNC: en tanto órgano de gobierno que refleja la participación de todos los estamentos universitarios en los procesos de toma de decisiones, consideramos fundamental que revise, debata y apruebe este documento. La aprobación del Protocolo por parte de este espacio de gobierno universitario le otorgará la legitimidad e institucionalidad necesarias para garantizar su reconocimiento como dispositivo institucional y su consecuente aplicación.

El Protocolo de Accesibilidad Urbana y Edilicia constituiría el quinto protocolo institucional sobre accesibilidad que se apruebe por el Honorable Consejo Superior de la UNC. Configurando con los cuatro restantes un único corpus integral en la materia y un marco regulatorio para su abordaje en la UNC. Hacemos referencia a los Protocolos de Actuación sobre Estrategias Pedagógicas Inclusivas, Situaciones de Evaluación y sobre Accesibilidad Comunicacional en Actividades Académicas, aprobados a través de las Resoluciones del HCS № 1386, 1389 y 1390, respectivamente, en el año 2010. Y al Protocolo de pautas para la supresión de barreras culturales que condicionan el uso de los espacios comunes, aprobado por la Resolución del HCS $\mathrm{N}^{\circ} 1605$ en el 2011.

b. Realizar talleres de difusión, formación y reflexión sobre el Protocolo: orientados a la apropiación de su contenido por parte de los directivos y equipos técnicos de las áreas de Planeamiento, Infraestructura, Seguridad e Higiene de las unidades académicas y dependencias de la UNC. Entendemos a estos talleres como espacios institucionales de socialización y diálogo, que posibilitarán el intercambio colectivo respecto a la accesibilidad urbana y edilicia, por parte de los diferentes actores institucionales implicados en procesos de diseño, planificación y construcción del espacio universitario.

Además de la formación en la materia y la difusión de la relevancia institucional del Protocolo, estos espacios supondrán la reflexión y revisión permanente de las pautas de accesibilidad, la generación de nuevos interrogantes que nos permitan advertir problemáticas aún no identificadas, y la construcción colaborativa de nuevas propuestas en base a experiencias concretas.

c. Promover la creación de una Comisión de Accesibilidad Urbana y Edilicia: Esta Comisión constituirá un espacio institucional de asesoramiento, información y diseño de propuestas de ejecución, conforme a lo dispuesto en el Protocolo de Accesibilidad Urbana y Edilicia y en la Ley Nacional No 24.314 y su Decreto Reglamentario No 914/97. En ese sentido, será un espacio interdisciplinario de colaboración permanente con la Subsecretaría de Planeamiento Físico de la Secretaría de Planificación y Gestión Institucional, para la elaboración de estrategias y lineamientos de actuación en materia de accesibilidad, así como, para la unificación de criterios de accesibilidad universal, seguridad y comunicación. De esta manera, se presenta como la condición de posibilidad para la efectiva implementación del mencionado Protocolo en la UNC. 
Consideramos fundamental que esta Comisión, propicie la participación activa de personas en situación de discapacidad (estudiantes, docentes, no docentes) en la identificación y supresión de barreras urbanas, edilicias y comunicacionales. Ya que la articulación de las potenciales respuestas técnicas con la percepción de las personas que cotidianamente deben sortear diversas barreras, garantiza la pertinencia de esas respuestas y sus condiciones de usabilidad.

Por otro lado, estimamos oportuno que esta Comisión forme parte de un espacio mayor de planificación del espacio edilicio y urbano de la UNC, que promueva un abordaje integral e integrado. De este modo, la accesibilidad, la seguridad, la gestión ambiental y el ordenamiento territorial se abordarían como ejes transversales al planificar el crecimiento y regulación del espacio urbano y edilicio de la universidad. Este espacio mayor de planificación podría tener la entidad de "Consejo Asesor" y estar conformado, además, de la Comisión de Accesibilidad Urbana y Edilicia, por las actuales Comisión de Ordenamiento Territorial, Unidad Central de Gestión Ambiental Sustentable y Consejo para la Prevención de la Seguridad.

Como puede observarse, las tres propuestas suponen, por un lado, preservar y afianzar los principios de interdisciplinariedad y producción multiactoral, transversales al proceso transitado, que entendemos debieran orientar la gestión de dispositivos institucionales, como el Protocolo, en las instituciones de educación superior. Sostenemos que el diseño participativo constituye la herramienta fundamental para encontrar soluciones apropiadas a problemáticas complejas.

Por el otro, promover de manera prioritaria la incorporación de herramientas conceptuales y técnicas para la resolución de problemáticas emergentes o situaciones no previstas en el Protocolo, en los directivos y equipos técnicos de las áreas de Planeamiento, Infraestructura, Seguridad e Higiene de las unidades académicas y dependencias de la UNC. Y no solamente el mero cumplimiento de las pautas de accesibilidad que este establece.

\section{Bibliografía}

ABBERLEY, Paul, "Trabajo, Utopía y Deficiencia", en BARTON, Len (comp.) Discapacidad y Sociedad. Madrid, Ed. Morata, 1998, pp. 78-95. ISBN: 84-7112-434-3.

ABRAMOVICH, Víctor, "Una aproximación al enfoque de derechos en las estrategias y políticas de desarrollo", en Revista CEPAL, N 88, Santiago de Chile, 2006, pp. 35-50. ISBN: 92-1-322813-9.

ALONZO LÓPEZ, Fernando (coord.), Libro verde. La accesibilidad en España. Diagnóstico y bases para un plan integral de supresión de barreras, $1^{\circ}$ edición, Madrid, Ministerio de Trabajo y Asuntos Sociales, Instituto de Migraciones y Servicios Sociales (IMSERSO), 2002, 341 págs. ISBN: 84-8446-048-7.

ALONZO LÓPEZ, Fernando (coord.), Libro blanco de la accesibilidad, Madrid, Ministerio de Trabajo y Asuntos Sociales, Instituto de Migraciones y Servicios Sociales (IMSERSO), 2003, 240 págs.

ALONSO LÓPEZ, Fernando, "Algo más que suprimir barreras: conceptos y argumentos para una accesibilidad universal", en TRANS: Revista de Traductología, № 2, Universidad de Málaga, España, 2007 a, pp. 15-30. ISSN: 1137-2311.

ALONZO LÓPEZ, Fernando, "Los ejes determinantes de las políticas de igualdad de oportunidades: La accesibilidad universal y el diseño para todos", en De Lorenzo, R. y Cayo Pérez Bueno, L. Tratado sobre la Discapacidad, España, Editorial Aranzadi, 2007 b, pp. 1209-1234. ISSN: 978-84-8355-138-7.

ARAGAL, Francesc, "Participación de los usuarios en el proceso de diseño", en Dossier Revista Minusval, No 133, España, Ministerio de Trabajo y Asuntos Sociales, Instituto de Migraciones y Servicios Sociales (IMSERSO), 2002, pp. 32-33. ISSN: 0210-0622.

ASOCIACIÓN ESPAÑOLA DE NORMALIZACIÓN Y CERTIFICACIÓN, Norma ISO 9999:2007. Productos de apoyo para personas con discapacidad. Clasificación y terminología. Versión en español. [En línea]. 
Septiembre de 2007. [Fecha de consulta: 16 de junio de 2012]. Disponible en: http://www.catalogoceapat.org/UNE-EN_ISO_9999-2007.pdf

BARNES, Colin, "Las teorías de la discapacidad y los orígenes de la opresión de las personas discapacitadas en la sociedad occidental", en: BARTON, Len (comp.) Discapacidad y Sociedad, Madrid, Ed. Morata, 1998, pp. 59-76. ISBN: 84-7112-434-3.

BARNES, Colin, "Vida Independiente: visión socio-política", en: GARCÍA ALONZO (coord) El Movimiento de Vida Independiente: Experiencias Internacionales, Madrid, Fundación Luis Vives, 2003, pp.61-69.

BARNES, Colin, "Understanding disability and the importance of design for all", en Journal of Accessibility and Design for All, N 1, Vol. 1, 2011, pp. 55-80. ISSN: 2013-7087.

BARTON, Len, "Estudios sobre discapacidad y la búsqueda de la inclusividad. Algunas observaciones", en Revista de Educación, N 349, editada por el Ministerio de Educación, Cultura y Deporte de España, 2009, pp. 137-152. ISSN: 0034-8082.

BATAVIA, Andrew, "Are people with disabilities an oppressed minority, and why does this matter?", en Journal of Disability Policy Studies, Vol.12, No 2, 2001, pp.66-67.

BOURDIEU, Pierre; Wacquant Loic, Las argucias de la razón imperialista, Buenos Aires, Editorial Paidós, 2001, 55 págs., ISBN: 84-493-1012-1.

CENTRO ESTATAL DE AUTONOMÍA PERSONAL Y AYUDAS TÉCNICAS (CEAPAT), Concepto europeo de accesibilidad, Madrid, Ministerio de Trabajo y Asuntos Sociales, IMSERSO, 1996, 35 págs.

CENTRO ESTATAL DE AUTONOMÍA PERSONAL Y AYUDAS TÉCNICAS (CEAPAT), Diseño para todos en España, Madrid, Boletín CEAPAT Nº 58, 2008, 16 págs.

CORIAT, Silvia, Otras miradas. Otros usuarios. En: Encuentro Regional de Accesibilidad y Universidad de las Facultades la Asociación de Facultades y Escuelas de Arquitectura Públicas del Mercosur (ARQUISUR): Accesibilidad: Compromiso Social y Responsabilidad Profesional para un Diseño Inclusivo. (1ㅇ, 2012, Buenos Aires, Argentina).Centro de Investigación de Barreras Arquitectónicas, Urbanísticas y en el Transporte (CIBAUT), Comisión Pro Medios Accesibles (COPROMA) de la Facultad de Arquitectura, Diseño y Urbanismo de la Universidad de Buenos Aires (UBA), Secretaría de Extensión de la Facultad de Arquitectura, Urbanismo y Diseño de la Universidad Nacional de Mar del Plata.

DE JONG, Gerben, "Independent Living: From Social Movement to Analytic Paradigm", en Archives of physical medicine and rehabilitation, Vol.60, Virginia, EEUU; 1979, pp. 435-446. ISSN: 0003-9993.

EGEA GARCÍA, Carlos; Sarabia Sánchez, Alicia, Experiencias de Aplicación en España de la Clasificación Internacional de Deficiencias, Discapacidades y Minusvalías, primera edición, Madrid, Documentos 58/2001. Real Patronato de Prevención y de Atención a Personas con Minusvalía, 2001, 190 págs.

EGEA GARCÍA, Carlos; Sarabia Sánchez, Alicia, "Visión y Modelos Conceptuales de la Discapacidad", en Revista Polibea, No 73, Madrid, 2004, pp. 29-42. ISSN: 1137-2192.

FARACI, Mariano, Plan de Reordenamiento Territorial y Espacio Público. Ciudad Universitaria. [En línea]. Universidad Nacional de Córdoba, Córdoba, 2012. [Fecha de consulta: 26 de enero de 2014]. Disponible en: http://400.unc.edu.ar/seccion/novedades/2012/octubre/unc-propuesta-reordenamiento-territorial-yespacio-publico-2012.pdf/at_download/file.

FINKELSTEIN, Victor, Attitudes and Disabled People: Issues for Discussion, New York, World Rehabilitation Fund., 1980, 64 págs.

FUNDACIÓN ONCE, Libro Blanco del Diseño para Todos en la Universidad, Madrid, Ministerio de Trabajo y Asuntos Sociales, Instituto de Migraciones y Servicios Sociales (IMSERSO), 2006, 172 págs. ISBN: 84689-6790-4 
GARCÍA ALONSO, José (coord.) Libro Blanco de la I+D+i al servicio de las personas con Discapacidad y las Personas Mayores. [En línea].España: CERMI-CEAPAT, 2003. [Fecha de consulta: 14 de junio de 2012]. Disponible en: http://www.ceapat.es/ceapat_01/centro_documental/productos_apoyo/IM_036173

HAHN, Harlan, "Toward a Politics of Disability: Definitions, Disciplines, and Policies", en Social Science Journal, No 4, Vol. 22, 1985, pp. 87-105. ISSN: 0362-3319.

HUMPHREY, Jill, "Researching disability politics. Or, some problems with the social model in the practice", en Disability \& Society, N 1, Vol.15, 2000, pp. 63-85. ISSN: 0968-7599.

HUNT, Judy, "A Revolutionary Group with a Revolutionary Message", en Greater Manchester of Disabled People's Magazine "Coalition", 2001, pp. 22-30.

IMRIE, Rob, "Universalism, universal design and equitable access to the built environment", en Disability \& Rehabilitation, No 34, Vol.10, 2012, pp. 873-882. ISSN: 0963-8288.

IMRIE, Rob, "Designing Inclusive Environments and the significance of Universal Design", en

Swain, J., French, S., Barnes, C. and Thomas, C., (eds.), Disabling Barriers, Enabling Environments, Sage Publications, London, 2013, pp. 287-296. ISBN: 1446258998.

IMRIE, Rob y Gaete Reyes, Mariela, "Universal Design", en: Burch, Susan, (ed.): Encyclopedia of American Disability History, 3 Vols. New York: Facts on File, 2009, pp. 919-921.

INSTITUTO NACIONAL DE ESTADÍSTICA Y CENSOS (INDEC), Censo Nacional de Población, Hogares y Viviendas, 2010. Resultados definitivos. [En línea]. [Fecha de consulta: 26 de enero de 2014]. Disponible en: http://www.censo2010.indec.gov.ar/resultadosdefinitivos.asp

INTERNATIONAL ORGANIZATION FOR STANDARDIZATION. Assistive products for persons with disability Classification and terminology, ISO 9999:2007. [En línea]. Marzo de 2007. [Fecha de consulta: 14 de diciembre de 2012]. Disponible en: http://www.iso.org/iso/catalogue_detail.htm?csnumber=38894

INTERNATIONAL ORGANIZATION FOR STANDARDIZATION. Assistive products for persons with disability Classification and terminology, ISO 9999:2011. [En línea]. Julio de 2011. [Fecha de consulta: 14 de diciembre de 2012]. Disponible en:

http://www.iso.org/iso/iso_catalogue/catalogue_tc/catalogue_detail.htm?csnumber $=50982$

MACE, Ronald; JONES, Mike; MUELLER, Jim; MULLICK, Abir; OSTROFF, Elaine; CONNEL, Bettye Rose; SANFORD, Jon; STEINFELD, Ed; STORY, Molly \& VANDERHEIDEN, Gregg, Los principios del Diseño Universal. Versión 2.0. [En línea]. N.C. State University, The Center for Universal Design, 1997. [Fecha de consulta: 25 de septiembre de 2011]. Disponible en:

http://www.ncsu.edu/www/ncsu/design/sod5/cud/index.htm

MACE, Ronald, Universal Design. Housing for the Lifespan of all People, The Center for Universal Design, Nort Carolina State University, 1988, 16 págs.

MACE, Ronald, A perspective on Universal Design. [En línea]. Institute for Human Centered Design, 1998. [Fecha de consulta: 25 de septiembre de 2011]. Disponible en:

http://www.humancentereddesign.org/index.php?option=Resource\&articleid=156\&topicid=28

MACE, Ronald; MUELLER, Jim \& STORY, Molly, The Universal Design File. Designing for People for All Ages and Abilities. [En línea]. NC State University, The Center for Universal Design, 1998. [Fecha de consulta: 29 de septiembre de 2011]. Disponible en: http://designdev.ncsu.edu/openjournal/index.php/redlab/article/viewFile/102/56

MAREÑO SEMPERTEGUI, Mauricio, Equidad en el acceso, permanencia, avance y egreso de personas en situación de discapacidad en la educación superior universitaria. Una propuesta de abordaje integral en la Universidad Nacional de Córdoba, Ponencia presentada en las "Jornadas sobre Accesibilidad, Derechos Humanos y Universidad. Accesibilidad como Derecho a la Educación", Facultad de Arquitectura, Diseño y Urbanismo de la Universidad de Buenos Aires, 2008. 
MAREÑO SEMPERTEGUI, Mauricio, "La discapacitación social del diferente", en Intersticios, Revista Sociológica de Pensamiento Crítico, 4(1): 2010, pp.95-105. ISSN 1887-3898.

MAREÑO SEMPERTEGUI, Mauricio, Las personas en situación de discapacidad y las Políticas de Empleo: algunos aportes para la gestión e implementación de políticas inclusivas. Informe final de consultoría. Programa de Apoyo a la Consolidación y Mejora de la Calidad del Empleo en la Argentina (CEA) de la Organización Internacional del Trabajo (OIT), en el marco de la asistencia técnica efectuada a la Secretaría de Empleo del Ministerio de Trabajo, Empleo y Seguridad Social de la Nación (MTEySS), 2011.

MORIN, Edgar, Introducción al pensamiento complejo. España, Editorial Gedisa, 2007.

OLIVER, Mike, "Social Policy and Disability: some theoretical issues", en Disability, Handicap \& Society, No 1, Vol. 1, 1986, pp. 5-7. ISSN: 0267-4645.

OLIVER, Mike, The Individual and Social Models of Disability. Paper presented at Joint Workshop of the Living Options Group and the Research Unit of the Royal College of Physicians. [En línea]. Centre for Disability Studies, University of Leeds. UK. 1990 a. [Fecha de consulta: 26 de septiembre de 2011]. Disponible en: http://disability-studies.leeds.ac.uk/files/library/Oliver-in-soc-dis.pdf

OLIVER, Mike, "Cultural Production of Impairment and Disability", en: The Politics of disablement. Londres, The Macmillan Press, 1990 b. [En línea] Centre for Disability Studies, University of Leeds. UK. [Fecha de consulta: 30 de octubre de 2011]. Disponible en: http://disabilitystudies.leeds.ac.uk/files/library/Oliver-p-of-d-Oliver2.pdf

OLIVER, Mike, "Disability definitions: the politics of meaning" en: The Politics of disablement. Londres, The Macmillan Press. 1990 c. [En línea] Centre for Disability Studies, University of Leeds. UK. [Fecha de consulta: 30 de octubre de 2011]. Disponible en: http://disability-studies.leeds.ac.uk/files/library/Oliverp-of-d-Oliver1.pdf

OLIVER, Mike, "¿Una sociología de la Discapacidad o una sociología discapacitada?" en: BARTON, Len (comp.) Discapacidad y Sociedad. Madrid, Ed. Morata, 1998, pp. 34-58. ISBN: 84-7112-434-3.

ORGANIZACIÓN MUNDIAL DE LA SALUD (OMS), Clasificación Internacional de Deficiencias, Discapacidades y Minusvalías. Manual de clasificación de la consecuencia de la enfermedad, Segunda Edición en castellano, Madrid, Editada por el Ministerio de Asuntos Sociales, Instituto Nacional de Servicios Sociales, 1994.

ORGANIZACIÓN MUNDIAL DE LA SALUD (OMS), Clasificación Internacional del Funcionamiento, la Discapacidad y la Salud (CIF). Programa Docente y de Difusión, Madrid, Editado por el Instituto Nacional de Servicios Sociales, 2001.

PALACIOS, Agustina; Romañach, Javier, El modelo de la diversidad. La Bioética y los Derechos Humanos como herramientas para alcanzar la plena dignidad en la diversidad funcional, España, Ediciones Diversitas - AIES, 2006, 249 págs., ISBN: 84-964-7440-2.

PAUTASSI, Laura; Gamallo, Gustavo (comp.), Más derechos, menos marginaciones: políticas sociales y bienestar en la Argentina, primera edición, Buenos Aires, Editorial Biblos, 2012, 346 págs., ISBN: 978987-691-070-5.

PROGRAMA DE ESTADÍSTICAS UNIVERSITARIAS, Síntesis Estadística 2012-2013. [En línea]. Secretaría de Asuntos Académicos. Universidad Nacional de Córdoba, Córdoba, 2013. [Fecha de consulta: 20 de enero de 2014]. Disponible en: http://www.unc.edu.ar/estudios/programassaa/estadisticas/sintesis_estadistica

RODRÍGUEZ-PORRERO, Cristina, "Diseño para todos: características, orígenes y retos"en Dossier Revista Minusval, No 133, España, Ministerio de Trabajo y Asuntos Sociales, Instituto de Migraciones y Servicios Sociales (IMSERSO), 2002, pp. 17-20. ISSN: 0210-0622. 
ROMAÑACH, Javier; Lobato, Manuel, Diversidad Funcional, nuevo término para la lucha por la dignidad en la diversidad del ser humano, España, 2005. [En línea] Foro de Vida Independiente [Fecha de consulta: 3 de marzo de 2012]. Disponible en: http://www.forovidaindependiente.org/node/45

SECRETARÍA DE POLÍTICAS UNIVERSITARIAS, Instructivo del Programa de Accesibilidad en Universidades Nacionales. [En línea]. Ministerio de Educación de la Nación, 2010. [Fecha de consulta: 16 de diciembre de 2012]. Disponible en:http://portales.educacion.gov.ar/spu/infraestructura-universitaria/programa-deaccesibilidad/instructivo/

SECRETARÍA DE POLÍTICAS UNIVERSITARIAS, Resolución de creación del Programa de Accesibilidad en Universidades Nacionales No 770/10. [En línea]. Ministerio de Educación de la Nación, 2010. [Fecha de consulta: 16 de diciembre de 2012]. Disponible en:

http://www.me.gov.ar/spu/guia_tematica/infraestructura_u/doc/Res_N_770-10.pdf

STEINFELD, Edward, The Future of Universal Design, IDEA Center, University at Buffalo, 2006 a. [En línea] [Fecha de consulta: 3 de diciembre de 2013]. Disponible en:

http://futureofud.wikispaces.com/Position+Paper+-+Steinfeld

STEINFELD, Edward, Universal Design and the International Classification of Functioning, Disability and Health (ICF), IDEA Center, University at Buffalo, 2006 b. [En línea] [Fecha de consulta: 3 de diciembre de 2013]. Disponible en: http://futureofud. wikispaces.com/UD+and+the+ICF

STEINFELD, Edward, "Universal Design", en Stone, J.H.; Blouin, M. (editors), International Encyclopedia of Rehabilitation. 2010. [En línea] [Fecha de consulta: 3 de diciembre de 2013]. Disponible en:

http://cirrie.buffalo.edu/encyclopedia/en/article/107/

STIKER, Henri-Jacques, "Cuando las personas discapacitadas trastornan las políticas sociales", en Esprit, No 259, diciembre de 1999. Traducción de Diego Fonti para la Revista Nombres. Córdoba. 2002.

UNION OF THE PHYSICALLY IMPAIRED AGAINST SEGREGATION (UPIAS), Policy Statement, 1976. [En línea] Centre for Disability Studies, University of Leeds. UK. [Fecha de consulta: 22 de octubre de 2012]. Disponible en: http://disability-studies.leeds.ac.uk/files/library/UPIAS-UPIAS.pdf

UNION OF THE PHYSICALLY IMPAIRED AGAINST SEGREGATION (UPIAS), Fundamental Principles of Disability, 1975. [En línea] Centre for Disability Studies, University of Leeds. UK. [Fecha de consulta: 22 de octubre de 2012]. Disponible en: http://disability-studies.leeds.ac.uk/files/library/UPIAS-fundamentalprinciples.pdf

UNIVERSIDAD NACIONAL DE CÓRDOBA, Protocolo de Actuación sobre Estrategias Pedagógicas Inclusivas. [En línea]. Honorable Consejo Superior Resolución № 1386/2010. [Fecha de consulta: 28 de diciembre de 2012]. Disponible en: http://www.unc.edu.ar/vidaestudiantil/inclusion/discapacidad

UNIVERSIDAD NACIONAL DE CÓRDOBA, Revista Hoy la Universidad. La UNC en sus 400 años. Entre el legado y el camino. Editado por la Prosecretaría de Comunicación Institucional, noviembre de 2012. ISSN: 1667-6289

VERDUGO ALONSO, Miguel Ángel, "La concepción de discapacidad en los modelos sociales", en Verdugo, M.A.; Jordán de Urríes, F. B. (Coords.). Investigación, innovación y cambio: V Jornadas Científicas de Investigación sobre personas con discapacidad, España, 2003, pp. 235-247. ISSN: 84-8196-190-6.

VIÑOLO, Carlos, Una ciudad más apropiada para todos. Artículo publicado en la sección "Pensar la universidad" del Diario La Voz del Interior. Martes 7 de agosto de 2007. 